\title{
Mecanismos de remediação dos hidrocarbonetos policíclicos aromáticos do petróleo utilizando microalgas e cianobactérias com vistas a bioeconomia circular
}

Remediation mechanisms of polycyclic aromatic petroleum hydrocarbons using microalgae and cyanobacteria with emphasis on circular bioeconomy

Mecanismos de remediación de hidrocarburos de petróleo policíclicos aromáticos utilizando microalgas y cianobacterias con vista a la bioeconomía circular

\section{Resumo}

A água produzida é um efluente da indústria de óleo e gás gerada em grandes quantidades. Seu descarte, sem o devido tratamento prévio, pode ocasionar impactos negativos não só ao meio ambiente como também à saúde humana. Isso ocorre porque a água produzida, além de possuir alta salinidade, é composta por metais pesados, partículas de óleos e compostos químicos com propriedades tóxicas. Dentre os seus componentes, os hidrocarbonetos policíclicos aromáticos (HPAs) são um dos grupos mais preocupantes. Os HPAs são poluentes orgânicos de natureza carcinogênica, recalcitrantes, que, apesar de sua toxicidade, podem ser removidos e degradados por microalgas e cianobactérias a partir de três mecanismos: ficoadsorção, ficossorção e ficodegradação. Mediante ao exposto, esta revisão tem por objetivo fornecer uma visão geral acerca dos mecanismos de remediação dos hidrocarbonetos policíclicos aromáticos (HPAs) por microalgas e cianobactérias. Esta revisão leva em consideração o ponto de vista da bioeconomia circular, onde a biomassa das microalgas e cianobactérias são consideradas uma potencial fonte de elementos essenciais para geração de bioprodutos como biocombustíveis e biopolímeros.

Palavras-chave: Água produzida; Biorrefinaria; Poluentes orgânicos persistentes; Tratamento biológico. 


\begin{abstract}
Produced water is an effluent from the oil and gas industry generated in large quantities. Its disposal without prior treatment can cause negative impacts not only to the environment but also to human health. This occurs due to the water's high salinity and composition that includes heavy metals, oil particles and chemical compounds with toxic properties. Among these compounds, polycyclic aromatic hydrocarbons (PAHs) are one of the most worrying groups. PAHs are recalcitrant, carcinogenic organic pollutants that, despite their toxicity, can be removed and degraded by microalgae and cyanobacteria through three mechanisms: phycoadsorption, phycosorption and phycodegradation. Based on the aforementioned, this review aims to provide an overview of the remediation mechanisms of polycyclic aromatic hydrocarbons (PAHs) by microalgae and cyanobacteria. This review takes into account the point of view of circular bioeconomy, where the biomass of microalgae and cyanobacteria is considered a potential source of essential elements for the generation of bioproducts such as biofuels and biopolymers.
\end{abstract}

Keywords: Produced water; Biorefinery; Persistent organic pollutants; Biological treatment.

\title{
Resumen
}

El agua de producción es un efluente de la industria del petróleo y gas generada en grandes cantidades. Su descarte sin el debido tratamiento previo, puede ocasionar impactos negativos no solo a el medio ambiente como también a la salud humana. Esto porque, el agua de producción además de poseer alta salinidad, está compuesta por metales pesados, partículas de petróleo y compuestos químicos con propiedades tóxicas. Dentro de estos compuestos, los hidrocarburos policíclicos aromáticos (HPAs) son uno de los grupos más preocupantes. Los HPAs son contaminantes orgánicos de naturaleza carcinogénica, recalcitrante, que, a pesar de su toxicidad, pueden ser removidos y degradados por microalgas y cianobacterias a partir de tres mecanismos: ficoadsorción, ficoabsorción y ficodegradación. Mediante lo expuesto, esta revisión tiene por objetivo proporcionar una visión general acerca de los mecanismos de remediación de los hidrocarburos policíclicos aromáticos (HPAs) por microalgas y cianobacterias. Esta revisión tiene en cuenta el punto de vista de la bioeconomía circular, donde la biomasa de microalgas y cianobacterias se considera una fuente potencial de elementos esenciales para la generación de bioproductos como biocombustibles y biopolímeros.

Palabras clave: Agua de producción; Biorrefinería; Contaminantes orgánicos persistentes; Tratamiento biológico.

\section{Introdução}

A água produzida é um subproduto gerado durante as operações de extração da indústria de petróleo e gás, correspondendo a cerca de $80 \%$ dos resíduos produzidos por esse setor e as suas características variam de acordo com o poço e as técnicas empregadas durante a extração (Das et al., 2019). Além do elevado volume de produção, a composição química desse efluente é potencialmente prejudicial à saúde humana pela presença de contaminantes perigosos, recalcitrantes e cancerígenos como metais pesados, fenóis, hidrocarbonetos alifáticos e aromáticos além dos hidrocarbonetos policíclicos aromáticos (Al-Ghouti, Al-Kaabi, Ashfaq \& Da'na, 2019; Lutzu et al., 2020).

Segundo o World Water Assessment Programme (2017) cerca de $80 \%$ de todas as águas residuais industriais são lançadas no meio ambiente sem qualquer tratamento prévio, podendo levar à degradação dos corpos d'água aquáticos introduzindo compostos orgânicos perigosos e tóxicos com efeitos prejudiciais para a saúde humana e para os ecossistemas. Devido aos riscos, faz-se necessário o tratamento dessa água antes do lançamento final (Lu et al., 2015; WWAP, 2017).

Partindo de um ponto de vista de biorrefinaria e considerando a bioeconomia circular, a água produzida pode ser utilizada como fonte de recurso nutricional para o cultivo de microrganismos fotossintetizantes, se tornando uma fonte acessível e sustentável de água, energia, nutrientes e outros materiais recuperáveis para geração de produtos de alto valor agregado (UN WWDR, 2017).

A utilização de biotecnologias a base de microalgas e cianobactérias é caracterizada como um tratamento autossustentável, devido a capacidade de remover ou biodegradar os carbonos orgânicos e xenobióticos provenientes da água produzida bem como, a sua eficiência na acumulação de poluentes químicos e metais pesados (Suresh \& Ravishankar, 2004; Silva et al., 2015; Hammed, Prajapati \& S. e H Simsek, 2016; Moreira et al., 2016; Oliveira et al., 2020; Verâne et al., 2020). Aliado a esses fatores, o cultivo desses microrganismos se torna promissor pela redução do uso de grandes volumes de água 
necessário por essas culturas e a geração, no final do tratamento, de uma biomassa com potencial de reaproveitamento para geração de bioprodutos, contribuindo para uma bioeconomia circular (Wood, Miller, Sims \& Takemoto, 2015; Ammar, Khadim \& Mohamed, 2018; Dos Santos, Vieira, Zepka \& Jacob-Lopes, 2019).

A bioeconomia circular é uma economia onde são utilizados recursos biológicos para geração de produtos de alto valor agregado de forma sustentável, onde a recuperação de resíduos ou subprodutos de base biológica pode tanto prevenir a poluição ambiental quanto promover transformação potencial dos resíduos em produtos comercializáveis (Salvador et al., 2021). Devido a produção de biomassa de alto valor agregado, sua capacidade adaptativa a ambientes adversos e por captar o $\mathrm{CO}_{2}$ transformando-o em $\mathrm{O}_{2}$, as microalgas e cianobactérias têm se mostrado como microrganismos com processos biotecnológicos promissores para o cultivo em água residual e geração de bioprodutos provenientes da biomassa com possibilidade de aplicação industrial (Marques et al., 2020).

A partir dos fatores relacionados ao descarte de água residual sem tratamento adequado bem como aspectos relacionados à bioeconomia, esta revisão tem por objetivo fornecer uma visão geral acerca dos mecanismos de remediação dos hidrocarbonetos policíclicos aromáticos (HPAs) por microalgas e cianobactérias em efluentes industriais em um modelo de biorrefinaria no âmbito da bioeconomia circular.

\section{Metodologia}

A metodologia baseou-se inicialmente no levantamento de dados científicos nas bases de dados internacionais como ScienceDirect, Springer Link, Scopus e Scielo, como também foram realizadas pesquisas de dados nacionais através do Portal Periódico da Capes, utilizando a combinação de palavras chaves, empregando os termos booleanos "AND" e "OR": "microalgae OR cyanobacteria AND photobioreactor OR open systems", "microalgae OR cyanobacteria AND autotrophic OR heterotrophic OR mixotrophic", "adsorption removal AND microalgae OR cyanobacteria", "microalgae OR cyanobacteria AND nutrients", "microalgae OR cyanobacteria AND produced water OR oilfield OR polycyclic aromatic hydrocarbons", "microalgae AND Petroleum AND bioeconomy", "microalgae OR cyanobacteria AND circular bioeconomy AND biorefinery", "microalgae OR cyanobacteria AND lipids extraction AND biodiesel", "microalgae OR cyanobacteria AND polyhydroxyalkanoates", "microalgae OR cyanobacteria AND phycomediation mechanisms", "microalgae OR cyanobacteria AND removal produced water AND phycoremediation", "polycyclic aromatic hydrocarbons", "microalgae OR cyanobacteria AND cell biology", "produced water" AND "circular bioeconomy".

Destaca-se que para a construção deste artigo foram consultados livros para reforçar as discussões sobre os mecanismos de remediação da água produzida utilizando microalgas e cianobactérias no âmbito da bioeconomia circular, como: "Algae and environmental sustainability" (Singh, Bauddh \& Bux, 2015), "Cultivo de microalgas marinhas: Princípios e aplicações" (Lourenço, 2006) e "Potencialidades e desafios do cultivo" (Andrade \& Filho, 2014). O suporte metodológico foi fornecido a pesquisa através da obra "Metodologia Científica: Ciência, Ensino, Pesquisa" (Estrela, 2018).

\section{Resultados e Discussão}

\section{1 Água produzida}

$\mathrm{Na}$ indústria de óleo e gás, a água produzida é um termo usado para a água associada ao petróleo durante o processo de extração (Al-Ghouti et al., 2019). É uma mistura de água injetada, água de formação, hidrocarbonetos e produtos químicos para tratamento. A água de formação é uma água encontrada junto com petróleo em reservatórios. É ligeiramente ácida e fica abaixo dos hidrocarbonetos em reservatórios porosos. Quando obtida através de poços onshore, a água produzida também inclui a água injetada, que é injetada no poço com a função de manter a pressão hidráulica e melhorar a recuperação do óleo (Igunnu \& Chen, 2014). 
É necessário que haja uma análise da composição e propriedades físicas da água produzida a fim de prever seu potencial impacto no meio ambiente. A água produzida é uma mistura altamente complexa de componentes inorgânicos e orgânicos em vários estados físicos (Tibbetts, Buchanan, Gawel \& Large, 1992).

Jiménez, Micó, Arnaldos, Medina e Contreras (2018) analisaram a composição da água produzida a partir de revisão bibliográfica: os principais grupos de constituintes preocupantes na água produzida são: sais (expressos como salinidade, sólidos totais dissolvidos e condutividade elétrica); óleo e graxa; BTEX, que significa benzeno, tolueno, etilbenzeno e xilenos; hidrocarbonetos policíclicos aromáticos (HPA); ácidos orgânicos; fenol; alguns compostos orgânicos e inorgânicos naturais, como cálcio, magnésio, sulfatos e bário, além de aditivos químicos usados na perfuração, fraturamento e operação do poço, que pode ter algumas propriedades tóxicas como biocidas, inibidores de corrosão. Bezerra, da Silva Oliveira, da Costa, da Silva e Pergher (2016) listaram metais presentes na água produzida em altas concentrações como $\mathrm{Co}, \mathrm{Cd}, \mathrm{Cr}, \mathrm{Mo}, \mathrm{Pb}$ e Zn.

O despejo da água produzida e os efeitos dos seus componentes tóxicos são uma problemática relevante da indústria de óleo e gás. Em operações offshore, a água produzida é principalmente descarregada no meio ambiente marinho. Pode afetar o ecossistema, os organismos vivos expostos aos constituintes tóxicos e consequentemente, o ser humano ao consumir espécies marinhas afetadas. Portanto, muitos países desenvolveram regulamentos e padrões ambientais rígidos para o descarte de água produzida (Kabyl, Yang, Abbassi \& Li, 2020).

Segundo a base de dados da ANP, em junho de 2021, a geração de água produzida foi cerca de 13,4 milhões de m $^{3}$ nos poços marítimos e cerca de 7,6 milhões de $\mathrm{m}^{3}$ nos poços terrestres (ANP, 2020). No Brasil, o tratamento desse efluente deve ser realizado de modo a atender a Resolução CONAMA 393/2007 (Brasil, 2007).

\subsubsection{Hidrocarbonetos Policíclicos Aromáticos}

Os hidrocarbonetos policíclicos aromáticos (HPA) são uma classe única de poluentes orgânicos persistentes constituídos por centenas de substâncias individuais. Esses compostos contêm dois ou mais anéis aromáticos fundidos feitos de carbono e átomos de hidrogênio (Douben, 2003). Eles são poluentes ambientais onipresentes gerados principalmente durante a combustão incompleta de materiais orgânicos como, carvão, óleo, gasolina e madeira (Bozlaker, Muezzinoglu \& Odabasi, 2008). Os HPAs demonstraram ser mutagênicos, teratogênicos e carcinogênicos, e sua toxicidade aumenta com seus pesos moleculares (Luo et al., 2014).

Em 1976, a Agência de Proteção Ambiental dos Estados Unidos (USEPA) fez a seleção de 16 HPAs como poluentes prioritários. O quadro 1, mostra a relação desses grupos prioritários, suas propriedades físico-químicas e características gerais: 
Research, Society and Development, v. 10, n. 11, e512101119954, 2021

(CC BY 4.0) | ISSN 2525-3409 | DOI: http://dx.doi.org/10.33448/rsd-v10i11.19954

Quadro 1 - Relação dos 16 Hidrocarbonetos Policíclicos Aromáticos e suas propriedades físico-químicas e características gerais.

\begin{tabular}{|c|c|c|c|c|c|c|c|c|c|c|}
\hline Nome & Estrutura & $\begin{array}{l}\text { Peso } \\
\text { molecular }\end{array}$ & $\begin{array}{l}\text { Ponto } \\
\text { de } \\
\text { Fusão }\end{array}$ & $\begin{array}{l}\text { Ponto de } \\
\text { Ebulição }\end{array}$ & Solubilidade & $\begin{array}{l}\text { Categoria } \\
\text { Carcinogênica }\end{array}$ & $\begin{array}{l}\text { Número } \\
\text { de anéis }\end{array}$ & $\mathbf{F M}$ & Kow & KOC \\
\hline Naftaleno & & 128,16 & 82 & 218 & 32 & A4 & 2 & $\mathrm{C} 8 \mathrm{H} 10$ & 3,4 & 3,11 \\
\hline Acenaftileno & & 152,20 & 94,1 & 279 & 4 & A4 & 3 & $\mathrm{C} 12 \mathrm{H} 8$ & 4,07 & 1,4 \\
\hline Acenafteno & & 154,21 & 95 & 279 & 7 & A4 & 3 & $\begin{array}{l}\mathrm{C} 12 \mathrm{H} 1 \\
0\end{array}$ & 3,92 & 3,66 \\
\hline Fluoreno & & 166,22 & 116 & 295 & 1,79 & A4 & 3 & $\begin{array}{l}\mathrm{C} 13 \mathrm{H} 1 \\
0\end{array}$ & 4,18 & 3,86 \\
\hline Fenantreno & & 178,22 & 99 & 340 & 1,42 & A4 & 3 & $\begin{array}{l}\text { C14H1 } \\
0\end{array}$ & 4,5 & 4,15 \\
\hline Antraceno & & 178,23 & 217,5 & 340 & 0,059 & A4 & 3 & $\begin{array}{l}\text { C14H1 } \\
0\end{array}$ & 4,6 & 4,15 \\
\hline Fluoranteno & & 202,24 & 108 & 375 & 0,26 & A4 & 4 & $\begin{array}{l}\mathrm{C} 16 \mathrm{H} 1 \\
0\end{array}$ & 5,22 & 4,58 \\
\hline Pireno & & 202,24 & 156 & 404 & 0,134 & A4 & 4 & $\begin{array}{l}\text { C16H1 } \\
0\end{array}$ & 5,18 & 4,58 \\
\hline Benzo[a]antraceno & & 228,28 & 162 & 438 & 0,012 & A4 & 4 & $\begin{array}{l}\text { C18H1 } \\
2\end{array}$ & 5,61 & 5,3 \\
\hline Criseno & & 228,29 & 255 & 448 & 0,0019 & A4 & 4 & $\begin{array}{l}\text { C18H1 } \\
2\end{array}$ & 5,91 & 5,3 \\
\hline $\begin{array}{l}\text { Benzo[b] } \\
\text { fluoranteno }\end{array}$ & & 252,32 & 167,5 & 481 & 0,014 & A4 & 5 & $\begin{array}{l}\mathrm{C} 20 \mathrm{H} 1 \\
2\end{array}$ & 6,12 & 5,74 \\
\hline $\begin{array}{l}\text { Benzo[k] } \\
\text { fluoranteno }\end{array}$ & & 252,32 & 215,7 & 480 & 0,004 & A2 & 5 & $\begin{array}{l}\mathrm{C} 20 \mathrm{H} 1 \\
2\end{array}$ & 6,84 & 5,74 \\
\hline Benzo[a] pireno & & 252,30 & 179 & 495 & 0,038 & A2 & 5 & $\begin{array}{l}\mathrm{C} 20 \mathrm{H} 1 \\
2\end{array}$ & 6,5 & 6,74 \\
\hline $\begin{array}{l}\text { Indeno[1,2,3- } \\
\text { cd]pireno }\end{array}$ & & 276,34 & 163 & 536 & 0,062 & A2 & 6 & $\begin{array}{l}\mathrm{C} 22 \mathrm{H} 1 \\
2\end{array}$ & 6,58 & 6,2 \\
\hline $\begin{array}{l}\text { Dibenzo[a,h] } \\
\text { antraceno }\end{array}$ & & 278,35 & 267 & 524 & 0,0005 & A2 & 5 & $\begin{array}{l}\mathrm{C} 22 \mathrm{H} 1 \\
4\end{array}$ & 6,5 & 6,52 \\
\hline $\begin{array}{l}\text { Benzo[g,h,i] } \\
\text { perileno }\end{array}$ & & 276,34 & 277 & 550 & 0,0026 & A4 & 6 & $\begin{array}{l}\text { C21H1 } \\
6\end{array}$ & 7,1 & 6,2 \\
\hline
\end{tabular}

Fonte: USEPA (2008). 
Os HPAs podem ser classificados de acordo com seus números de anel de benzeno, isto é, 2-3 anéis para baixo peso molecular (LMW-HAPs) e 4-7 anéis para alto peso molecular (HMW-HPAs) respectivamente. Os compostos LMW contendo 2 ou 3 anéis, apresentam toxicidade aguda significativa, são relativamente mais voláteis e mais solúveis em água em comparação com os HMW (Mallick, Chakraborty, \& Dutta, 2011), enquanto muitos HMW contendo 4 a 7 anéis, possuem propriedades carcinogênicas, mutagênicas ou teratogênicas para um grande número de organismos diferentes. Os HMW são de preocupação ambiental especial e mais perigosos do que os LMW. De fato, devido ao seu maior número de anéis de benzeno, HMW (como pireno, benzo[a]antraceno, benzo[a]pireno) exibem recalcitrância mais significativa aos processos de degradação e mais características de toxicidade do que o LMW grupo (tal como naftaleno, fenantreno, antraceno) (Ferraro et al., 2021).

Os HPAs podem ser degradados através dos processos de fotodegradação e biodegradação que ocorrem por ação de microorganismos e de metabolismo na biota superior (Douben, 2003). O HPA foi selecionado como parâmetro de análise da eficiência do processo de biorremediação da água produzida devido a sua toxicidade e, consequentemente, o potencial impacto do despejo no meio ambiente sem o tratamento correto.

\subsection{Microalgas e cianobactérias}

As microalgas e cianobactérias são organismos microscópicos e fotossintetizantes que possuem uma alta adaptabilidade a uma variedade de ambientes aquáticos e sistemas de cultivo. Somado a esse aspecto, esses microrganismos são objetos de investigação de diversos estudos devido ao seu alto potencial biotecnológico para a remoção de contaminantes externos aliado à produção de produtos de alto valor que podem ser gerados a partir de componentes presentes na composição da sua matéria orgânica. Assim, o estudo acerca do metabolismo e compostos presentes nesses microrganismos se torna essencial para o desenvolvimento de uma economia de base biológica no futuro (Collins, Alvarez \& Chauhan, 2014; Shih, 2018; Singh, Kaur, Bansal, Kapur \& Sundaram, 2020).

As microalgas são organismos unicelulares com dimensões microscópicas com uma ampla versatilidade na adaptação em diversos ecossistemas. Possuem uma variedade de classes que se diferenciam pela composição bioquímica, ciclo de vida além de suas características morfológicas que permitem que esses microrganismos sejam resistentes às condições ambientais extremas como a alta salinidade, altas e baixas temperaturas, deficiência de nutrientes, irradiação e estresse osmótico (Holzinger \& Karsten, 2013; Andrade \& Collozi Filho, 2014).

Esses microrganismos possuem uma estrutura mais complexa que as cianobactérias e uma maior função celular. A estrutura da célula eucariótica é composta, de maneira geral, pelo citoplasma e parede celular, sendo essa estrutura comumente espessa e rígida, podendo ter suas características alteradas de acordo com a espécie de microalga e, em condições estressantes, por exemplo, a sua parede pode aumentar em massa e gerar, por consequência, um acúmulo de lipídeos no interior do citoplasma - componente importante em diversos processos biotecnológicos (Singh \& Saxena, 2015; Posten \& Chen, 2016). É composta também por componentes associados - cloroplasto, mitocôndria, vacúolo, amido, lipídios, pigmentos fotossintéticos e o núcleo celular contendo informações genéticas (Alberts et al., 2002; Posten \& Chen, 2016).

Enquanto que, as cianobactérias são consideradas organismos procariontes fotossintéticos que possuem uma estrutura simples, sem a presença de membrana interna e núcleo associado (Singh et al., 2020). São consideradas uma das formas de vida mais primitivas, possuem uma flexibilidade de ocupar ambientes aquáticos e terrestres e algumas espécies são capazes de fixar o nitrogênio gasoso como amônia e nitrato apresentando um elevado potencial biotecnológico (Sharma, Rai \& Stal, 2013; Subramaniyan, 2012).

Somado a esses aspectos, as cianobactérias possuem uma membrana celular externa formada por fosfolipídios, lipoproteínas e lipopolissacarídeos, pelo citoplasma contendo a informação genética, ribossomos, inclusões e pigmentos fotossintéticos com composição variável formado pela clorofila e ficobiliproteínas como a ficocianina, ficoeritrina, 
aloficocianina (Verma \& Agarwal, 2004; Pollard, Earnshaw, Lippincott-Schwartz \& Johnson, 2016). A configuração e estrutura celular das microalgas e cianobactérias, previamente descritas, são apresentadas na Figura 1.

Figura 1 - Estrutura celular das microalgas e cianobactérias.

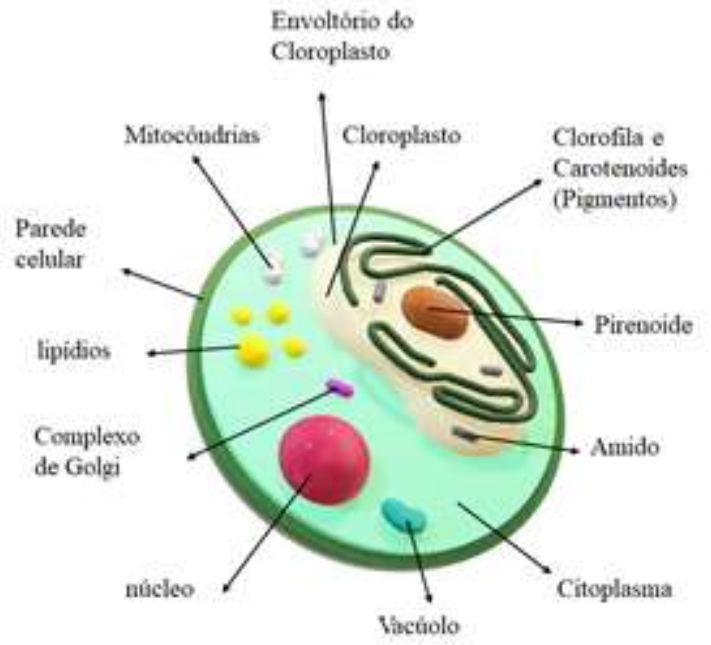

Microalga

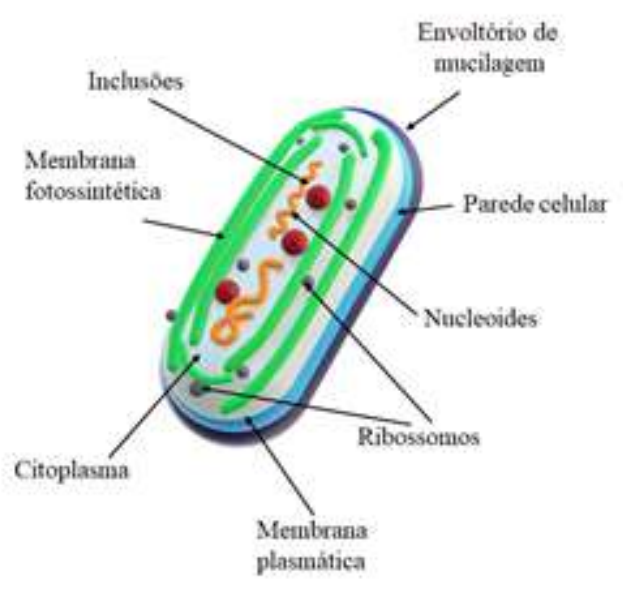

Cianobactéria

Fonte: Adaptado de Pignolet et al. (2013).

Esses aspectos estruturais e morfológicos apresentados conferem a possibilidade dos microrganismos de produzirem metabólitos intracelulares como ácidos graxos, carboidratos, pigmentos fotossintetizantes, proteínas e lipídios capazes de produzir produtos de base biológica com aplicação industrial (Deviram et al., 2020). As microalgas e cianobactérias podem remediar os nutrientes presentes nas águas residuais, reduzindo a toxicidade e contaminação dos corpos d'água pela carga orgânica presente nesses efluentes (Collins et al., 2014; Dos Santos et al., 2019).

\subsubsection{Principais nutrientes}

Para que as microalgas e cianobactérias possam crescer e gerar biomassa, um dos fatores importantes é suprir a necessidade nutricional desses seres levando em consideração cada espécie. Os nutrientes básicos para cultivo destes microrganismos são carbono, nitrogênio, hidrogênio, oxigênio, fósforo, magnésio, enxofre, potássio, cálcio, cobre, zinco e molibdênio. Como o metabolismo varia para cada tipo de microalga, haverá uma concentração ideal das substâncias citadas para diferentes processos metabólicos (Lourenço, 2006; Markou \& Georgakakis, 2011). Além disso, os nutrientes podem ser classificados como macronutrientes e micronutrientes: Os macronutrientes são aqueles consumidos em maior concentração nos processos metabólicos, enquanto os micronutrientes são aqueles que participam desses processos em menor concentração, auxiliando a absorção dos macronutrientes e da luz (Procházková, Brányiková, Zachleder \& Brányik, 2014).

Para que as microalgas e cianobactérias possam realizar a remoção dos hidrocarbonetos de forma eficiente, é importante estar atento às proporções ideais entre carbono, nitrogênio e fósforo que são elementos essenciais no cultivo das microalgas e cianobactérias. Para as microalgas a proporção ideal é de 56:9:1 (carbono, nitrogênio e fósforo) (Ji et al., 2013; Xin, Ying, Ke \& Ying-Xue, 2010, Miao et al., 2016, Zhang, Zhou, Burnap \& Peng, 2018).

Um dos elementos nutricionais essenciais é o carbono (C) por estar presente nas proteínas, lipídios e carboidratos e a sua falta limitar tanto o crescimento das microalgas quanto o acúmulo dessas substâncias nas células microalgais, sendo fundamental o seu fornecimento (Zhou, Lu, $\mathrm{Han} \& \mathrm{Li}, 2020)$. Fonte de carbono inorgânico como dióxido de carbono $\left(\mathrm{CO}_{2}\right)$ é 
usualmente utilizada por este gás estar presente no ar, mas outras fontes, como bicarbonato, também são usadas. (Zhai et al., 2020). Além disso, algumas espécies de microalgas e cianobactérias são capazes de assimilar o carbono orgânico, como hidrocarbonetos do petróleo presentes na água produzida (Ammar et al., 2018; Wood et al., 2015). A utilização de fontes de carbono da água produzida pode reduzir os custos da produção de microalgas e auxiliar no tratamento da mesma.

O nitrogênio (N) é fundamental para a composição genética dos microrganismos (DNA e RNA) e moléculas armazenadoras de energia, além da síntese de proteínas. Sua maior absorção contribui para o metabolismo intracelular e, consequentemente, o crescimento das células. As microalgas podem assimilar o nitrogênio presentes no nitrato, amônio e nitrogênio orgânico (Jeyakumar, Asha, Varalakshmi \& Kathiresan, 2020). O amônio é a fonte de nitrogênio predileta das microalgas por proporcionar menos gasto energético em sua assimilação (Su, 2021).

Segundo Marques et al., no experimento para remoção de hidrocarbonetos aromáticos policíclicos contidos em água produzida utilizando a microalga Nannochloropsis oculata, constatou-se que o meio de cultivo contendo HPAs havia menor quantidade de nitrogênio o que interferiu no crescimento da microalga, mas não as impediu de remover o carbono orgânico (Marques, Oliveira, Oliveira, Sales \& Moreira, 2021). Existem estudos que comprovam que a deficiência de nitrogênio após certo tempo de cultivo eleva a produção de ácidos graxos, mas diminui a quantidade de biomassa. Isso ocorre porque a eficiência fotossintética fica comprometida, redirecionando o carbono para produção de lipídios (Lam et al, 2017).

$\mathrm{O}$ fósforo $(\mathrm{P})$ é outro elemento importante para o metabolismo das microalgas, apesar de estar presente em menores quantidades na biomassa (Zhou et al., 2020). Geralmente podem ser consumidos como fósforo inorgânico (como íon fosfato, dihidrogenofosfato e hidrogenofosfato) e são imprescindíveis na síntese de fosfolipídios, ácidos nucleicos e fosfatos de éster de microalgas (Dyhrman et al., 2016). Em sistemas onde há deficiência de nitrogênio, a concentração ideal de fósforo beneficia a produtividade de lipídios, se a falta de ambos se somarem, isso afetará na produtividade de lipídios (Chu et al., 2013).

\subsubsection{Condições de cultivo: autotrófico, heterotrófico e mixotrófico}

As microalgas e cianobactérias são capazes de crescer em condições simples, essas condições são chamadas de fotoautotrófica, ou autotrófica, e são amplamente empregadas por utilizarem a luz solar como fonte de energia e carbono inorgânico como fonte de carbono celular (Neilson et al., 1974; Subashchandrabose, Ramakrishnan, Megharaj, Venkateswarlu \& Naidu, 2013). No entanto, a produção eficiente em grande escala é limitada pela penetração da luz, seja em lagoas abertas ou fotobiorreatores, uma vez que com o aumento da densidade celular pode ocorrer o auto sombreamento (Lowrey, Brooks \& McGinn, 2014). Além disso, apesar do gás carbônico $\left(\mathrm{CO}_{2}\right)$ estar presente na atmosfera, a concentração é de cerca de $0,04 \%$, o que não garante o fornecimento suficiente de carbono para o crescimento das microalgas, havendo a necessidade de fontes externas de $\mathrm{CO}_{2}$ concentrado (Smith, Bangert, Wilkinson \& Gilmour, 2015).

Em contrapartida, microalgas e cianobactérias são capazes de crescer na ausência da energia luminosa utilizando o metabolismo heterotrófico. Esta é uma alternativa de cultivo frente às limitações existentes da autotrofia (Chen, 1996; Morales-Sánchez, Martinez-Rodriguez, Kyndt \& Martinez, 2014; Subashchandrabose et al., 2013). No cultivo heterotrófico, esses microrganismos obtêm tanto o carbono celular quanto a energia a partir de uma fonte de carbono orgânico, independente da disponibilidade de luz, o que pode acarretar em uma maior densidade celular e, consequentemente, uma maior viabilidade da produção de biomassa em larga escala, caso o meio tenha as condições apropriadas para a espécie escolhida (Neilson et al., 1974; Perez-Garcia, Bashan, \& Esther Puente, 2011; Di Caprio, Altimari, Iaquaniello, Toro \& Pagnanelli, 2019; MoralesSánchez, Tinoco-Valencia, Kyndt \& Martinez, 2013). Porém, nem todas as espécies possuem esse metabolismo, existindo mais espécies autotróficas obrigatórias do que heterotróficas (Perez-Garcia, Escalante, de-Bashan \& Bashan, 2011).

Além de uma alta densidade celular, o cultivo heterotrófico pode também melhorar o acúmulo de substâncias nutricionais, como os carboidratos e lipídios, sendo este último um fator importante para a produção e viabilidade de 
biocombustíveis (Lowrey et al., 2014; Morales-Sánchez et al., 2014; Murwanashyaka et al., 2020). A composição do meio é um aspecto fundamental para isso. Os meios de cultura para o crescimento heterotrófico e autotrófico são semelhantes, com a diferença de que no primeiro é necessário o acréscimo de uma fonte de carbono orgânico (Perez-Garcia, Escalante et al., 2011). Um dos substratos mais utilizados é a glicose por ser rapidamente consumida pelas microalgas.

Lu, Wang, Yang, Zhu e Pan (2017) estudaram o crescimento da microalga Tetraselmis chuii em meio suplementado com glicose, com variadas razões entre carbono e nitrogênio, e observaram uma alta taxa de crescimento heterotrófico, com valores de densidade óptica entre 0,85 e 1,11, em comparação com valores em torno de 0,2 do crescimento autotrófico. Analisaram também a composição de nutrientes nas microalgas para as diferentes relações C:N, notando que com o aumento desta, o teor de lipídios aumentou, e para C:N igual a 12, T. chuii apresentou biomassa máxima, com peso seco de 1,37 $\pm 0,004$ $\mathrm{mg} \mathrm{mL} \mathrm{m}^{-1}$, valor este quase cinco vezes maior que no cultivo autotrófico. No entanto, o uso apenas de glicose seria caro para a produção em maiores escalas, podendo representar cerca de $80 \%$ do custo do meio (Li, Xu \& Wu, 2007).

Outros substratos de carbono que podem ser utilizados são acetato, glicerol, solução hidrolisada de celulose, amido e águas residuais de atividades municipais, agrícolas ou industriais (Lowrey et al., 2014). Este último tem recebido muito interesse devido à vantagem de não apenas prover nutrientes para as microalgas e cianobactérias (como carbono, nitrogênio e fósforo), como também remover poluentes desta. No entanto, essas águas podem conter contaminantes que inibam o crescimento desses microrganismos (Subashchandrabose et al., 2013).

El-Sheekh e Hamouda (2014) estudaram a capacidade das cianobactérias Spirulina platensis e Nostoc punctiforme de crescerem heterotroficamente, utilizando como fonte de carbono apenas o óleo bruto. Eles observaram que ambas se desenvolveram no meio, no entanto, $N$. punctiforme obteve melhores resultados de crescimento com uma menor concentração de óleo, o que pode ter ocorrido devido à maior toxicidade do meio com o aumento da quantidade desse poluente. Além disso, após realizadas análises apropriadas do meio, eles observaram que essas espécies de cianobactérias foram capazes de degradar os compostos alifáticos presentes, o que mostra a eficiência desses microrganismos para biorremediação, inclusive de ambientes contaminados por petróleo.

Murwanashyaka et al. (2020) propuseram um modelo matemático que relacionasse os substratos presentes em águas residuais com a geração de biomassa de microalgas, analisando não apenas a remoção de nutrientes e acúmulo de carboidratos e lipídios, como também o efeito da relação de C, $\mathrm{N}$ e P. Para isso, eles simularam águas residuais com diferentes razões de nutrientes para o crescimento da microalga Chlorella sorokiniana, obtendo produtividade máxima de $1,2145 \mathrm{~g} \mathrm{~L}^{-1} \mathrm{~h}^{-1}$, quando a razão foi de 192,3:5,1:1, para C, N e P, respectivamente. Para essa produtividade, os conteúdos de carboidratos e lipídios foram de 1,869 $\mathrm{g} \mathrm{L}^{-1}$ e $0,656 \mathrm{~g} \mathrm{~L}^{-1}$, respectivamente, com eficiência de remoção de 78,71\% de carbono, 88,83\% de nitrogênio e $61,95 \%$ de fósforo. Com esse estudo é possível verificar como a relação e disponibilidade dos nutrientes presentes no meio afetam a produtividade, acúmulo de substâncias nas microalgas e também a eficiência de biorremediação.

Apesar da possibilidade de maior produção de biomassa e também de algumas substâncias nutricionais resultantes do metabolismo heterotrófico das microalgas, existem algumas limitações dessas condições: a ausência de luz diminui a capacidade de produção de pigmentos e fitoquímicos de alto valor; contaminação da cultura por microrganismos indesejados, os quais competem pelo carbono orgânico presente no meio e, por isso, necessidade de esterilização; maiores custos com os substratos para atender à necessidade de carbono (Chen, 1996; Di Caprio et al., 2019; Morales-Sánchez et al., 2013).

A concentração e rendimento de biomassa das microalgas e cianobactérias podem ser maximizados quando estes microrganismos conseguem assimilar tanto o carbono orgânico quanto o inorgânico, simultaneamente, na presença de luz natural ou artificial (Neilson et al., 1974; Yu, Jia \& Dai, 2008). A mixotrofia é a combinação do metabolismo autotrófico e heterotrófico, a qual pode ser vantajosa diante à limitação de iluminação do primeiro e também reduzir a quantidade de substrato orgânico em comparação ao segundo (Smith et al., 2015). Juntamente à capacidade das microalgas crescerem em 
ambientes sob condições extremas, o cultivo mixotrófico pode ser aproveitado para o tratamento de água residual, uma fonte barata de carbono orgânico e outras substâncias necessárias para as células microalgais, e geração de bioprodutos com custos reduzidos, visto que o metabolismo mixotrófico possibilita o aumento da produtividade de biomassa (Subashchandrabose et al., 2013).

Yu et al. (2008) estudaram o crescimento da cianobactéria Nostoc flagelliforme em condições fotoautotróficas (na presença de luz, sem adição de carbono orgânico), heterotróficas (adicionando glicose ao meio no escuro) e mixotróficos (com suplementação de glicose na presença de luz), obtendo crescimento mais rápido para este último. O conteúdo de biomassa resultante do metabolismo mixotrófico foi de 1,67 $\mathrm{g} \mathrm{L}^{-1}$, sendo 2,28 e 4,98 vezes os rendimentos alcançados nas culturas heterotróficas e autotróficas, respectivamente. Além disso, a concentração celular em condições mixotróficas foi maior do que a soma dos valores obtidos a partir dos outros metabolismos de crescimento a partir do $5^{\circ}$ dia de cultivo.

Romero, Cordero e Garizado (2018) analisaram o crescimento e produção de biomassa da microalga Chlorella sp. em condições mixotróficas, utilizando diferentes concentrações de petróleo bruto como fonte de carbono, assim como o potencial de biodegradação dos hidrocarbonetos. Foram obtidos melhores resultados quando o meio continha uma concentração de $10 \mathrm{~g}$ $\mathrm{L}^{-1}$ de óleo, alcançando maior crescimento da microalga, alta produção de biomassa $\left(0,0786 \mathrm{~g} \mathrm{~mL}^{-1}\right)$ e pigmentos fotossintéticos, como carotenóides e clorofila (a), além de 96,64\% de remoção do petróleo presente no meio. Esse estudo mostrou que esses parâmetros analisados são influenciados pelas quantidades de poluentes, representando um impacto positivo em relação ao meio com ausência de óleo, no entanto, a partir de determinada concentração a produtividade diminui, visto que são componentes tóxicos e que podem inibir o desenvolvimento das microalgas.

\subsubsection{Sistemas de cultivo}

O cultivo de microalgas e cianobactérias em larga escala tem recebido maior atenção devido à ampla gama de bioprodutos que podem ser gerados a partir da biomassa, como: biocombustíveis, rações para animais e para a aquicultura, cosméticos, biofármacos (Ting et al., 2017; Parmar, Singh, Pandey, Gnansounou \& Madamwar 2011). Para reduzir o custo da cultura e aumentar a produtividade, busca-se por condições adequadas como a iluminação, a temperatura ideal, os nutrientes necessários para o crescimento e as cepas de microrganismos. Essas características, juntamente com a finalidade do cultivo e produto final desejado, são importantes para definir o tipo de cultivo e a geometria do fotobiorreator apropriado (Zhou et al., 2020). Existe uma grande variedade de sistemas de cultivo, estando divididos em sistemas abertos e fechados.

\subsubsection{Sistemas abertos}

Os sistemas abertos, onde as microalgas e cianobactérias são cultivadas em lagoas ou tanques ao ar livre, são muito utilizados porque possuem fácil e baixo custo de instalação e de operação (Chisti, 2007; Schenk et al., 2008; Johnson et al., 2018). No entanto, para a construção desses sistemas são necessárias grandes áreas e a produtividade é afetada por causa do risco de contaminação do meio com outros microrganismos, além da eficiência fotossintética ser reduzida devido à má distribuição da luz, principalmente com o aumento da profundidade da lagoa (Satyanarayana, Mariano \& Vargas, 2011).

Dentre os formatos utilizados ao ar livre, o mais popular é a lagoa com canaletas (raceway pond), que consiste em um tanque raso com pás circulares, bombas e defletores, garantindo a mistura dos nutrientes e evitando a sedimentação da cultura. Dessa forma, são obtidas boas taxas de crescimento das microalgas de forma contínua. Esses tanques podem ser construídos em vidro, tijolos, concreto ou plásticos, já que não é necessário o uso de material transparente (Schenk et al., 2008; PerezGarcia, Escalante et al., 2011), e possuem profundidade geralmente entre 15 e 50 centímetros (Ting et al., 2017), para que a luz penetre na água e seja absorvida pelas células de microalgas. 


\subsubsection{Sistemas fechados}

Com o intuito de solucionar os problemas referentes aos sistemas abertos, têm sido desenvolvidos fotobiorreatores fechados, os quais não permitem a transferência de massa direta entre o meio de cultivo e a atmosfera. Com isso há um maior controle da contaminação e, ao contrário dos tanques abertos, pode ser cultivada uma única espécie de microalgas (Chisti, 2007). Esses fotobiorreatores podem ser construídos em locais com luz natural ou em ambientes internos com o uso de luz artificial controlada, além de controlar a temperatura, $\mathrm{pH}$ e os nutrientes presentes no meio (Ting et al., 2017; Johnson et al., 2018).

Em contrapartida, estes têm como desvantagem os custos mais elevados de instalação e operação, o que dificulta a sua construção em larga escala. O consumo com a luz artificial contribui para esse custo mais elevado, sendo fundamental o desenvolvimento de sistemas que diminuam a relação entre o custo e a eficiência da iluminação no fotobiorreator. Para isso foram desenvolvidas técnicas, como o uso de luzes submersíveis ou guias de luz, que são inseridos dentro do meio de cultura com o intuito de aumentar a eficiência da iluminação (Erbland, Caron, Peterson \& Alyokhin, 2020; Sun et al., 2021).

Muitos estudos têm sido realizados para a construção desses sistemas fechados de modo a garantir a viabilidade do projeto. Isso porque os mesmos têm grande potencial na geração de produtos de alto valor agregado, como fármacos, cosméticos e alimentos para a saúde. Outro objetivo é o uso dos fotobiorreatores para o tratamento de águas residuais, fazendose necessário o ajuste dos parâmetros do fotobiorreator em relação àqueles projetados apenas para o cultivo das microalgas, devido à maior complexidade dessas águas e visando uma maior eficiência de remoção dos contaminantes, assim como o maior rendimento de biomassa (Ting et al., 2017).

Existem diversos tipos de sistemas fechados, sendo de grande importância a escolha da geometria mais adequada do fotobiorreator, com base nos parâmetros de cultivo. As diferentes configurações objetivam uma maior área de iluminação e, consequentemente, maior eficiência fotossintética e rendimento de biomassa. Dentre os mais comuns têm-se os fotobiorreatores de placa plana, tubular vertical e horizontal, cilíndrico e tanque agitado (Amaral et al., 2020; Fernández, Fernández-Sevilla, Moya, \& Grima, 2020; Yang et al., 2016).

$\mathrm{O}$ avanço das biotecnologias e a otimização dos fotobiorreatores como sistemas fechados, têm proporcionado seu uso para remediar locais contaminados com petróleo, principalmente para a remoção de hidrocarbonetos policíclicos aromáticos provenientes de derramamentos de petróleo ou da geração de água produzida em poços petrolíferos. Diante desses avanços, surge a técnica ficorremediação e seus mecanismos de remoção dos hidrocarbonetos.

\subsection{Ficorremediação}

A ficorremediação é considerada uma técnica que utiliza macroalgas, microalgas ou cianobactérias para a remoção ou biotransformação de poluentes, incluindo nutrientes, metais, xenobióticos e $\mathrm{CO}_{2}$, minimizando os impactos ambientais causados pela poluição (Singh, Bauddh \& Bux, 2015). As biotecnologias que utilizam como base microalgas e cianobactérias, são caracterizadas como tecnologias limpas, não intrusivas, seguras e autossustentáveis (Kumar \& Goud, 2021; Moreira \& Marques, 2020).

Segundo Lourenço (2006) a primeira alternativa desenvolvida para a remoção de contaminantes presentes na água utilizando microalgas foi em 1960, através de um sistema integrado entre bactéria-microalga para tratamento de efluentes domésticos com geração de oxigênio e energia (reciclando a água, carbono e nitrogênio para gerar metano e produzir energia elétrica). Desde então, as microalgas e cianobactérias têm se destacado como biotecnologias para remoção de poluentes em diferentes tipos de águas residuais, incluindo água produzida quanto aos hidrocarbonetos policíclicos aromáticos (Marques et al., 2021). 
A remoção de compostos presentes na matriz água é determinada através de mecanismos fisiológicos que incluem estratégias extracelular e / ou intracelular das microalgas e cianobactérias (Danouche, Ghachtouli, \& Arroussi, 2021). Esses mecanismos, assim como a técnica ficorremediação, são conceitos recentes e pouco conhecidos na literatura, mas que são amplamente conhecidos na biorremediação (que envolvem bactérias e fungos para degradar, reduzir ou eliminar os compostos orgânicos e inorgânicos presentes no ambiente). Esses mecanismos são conhecidos como: bioacumulação (pode ser denominado como ficoacumulação), biodegradação ou biotransformação (pode ser denominado como ficodegradação ou ficotransformação) e biosorção (pode ser denominado como ficosorção) como resumidos na Figura 2 (Nie et al., 2020; Danouche, Ghachtouli, \& Arroussi, 2021).

Figura 2 - Ilustração como atuam os mecanismos da ficorremediação (Extracelular: ficoadsorção e Intracelular: ficosorção, ficoacumulação e ficodegradação) utilizando microalgas e cianobactérias.

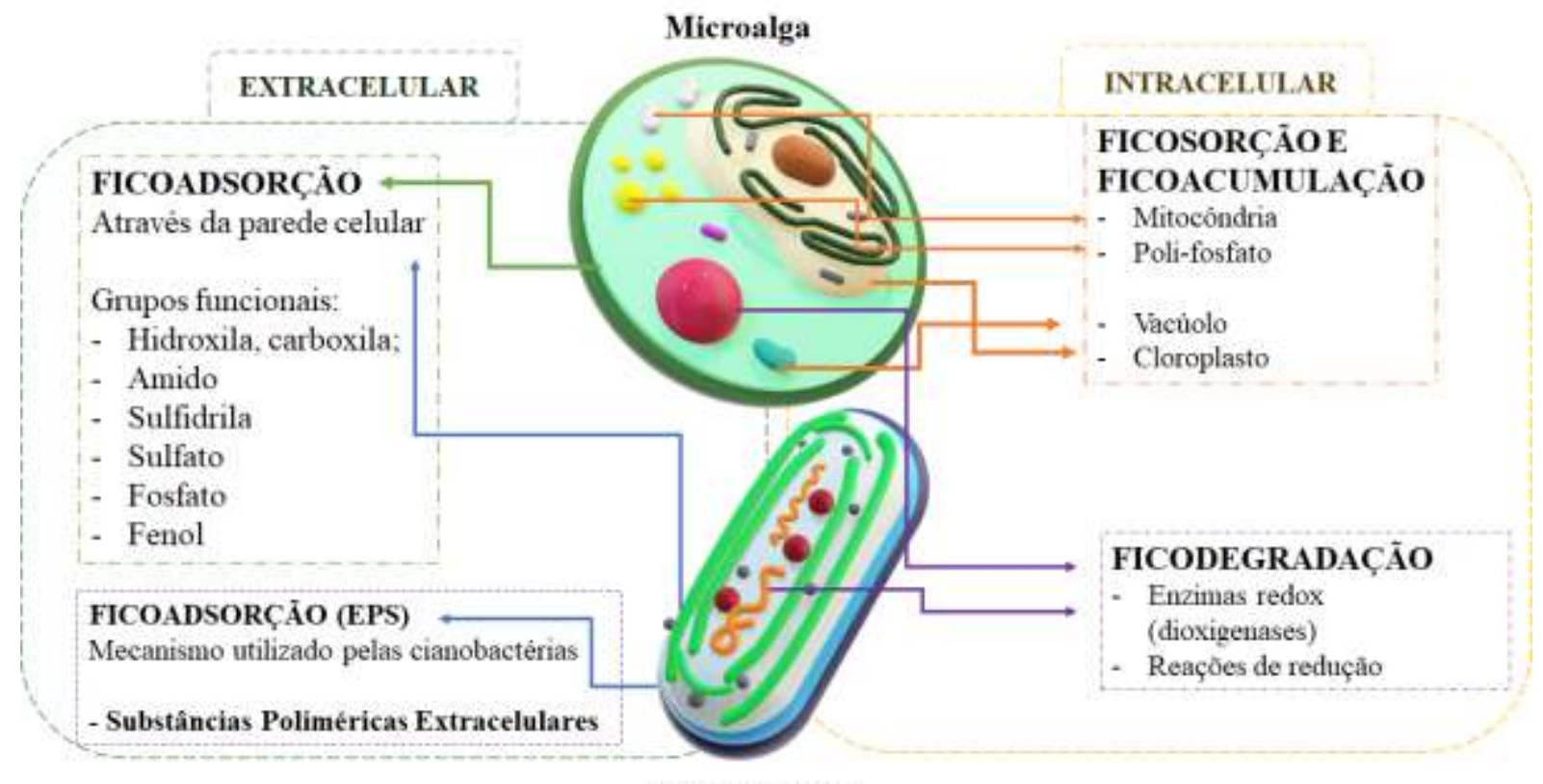

Cianobactéria

Fonte: Adaptado de Danouche et al. (2021).

\subsubsection{Mecanismos de remoção dos HPAs}

A remoção de HPAs por microalgas e cianobactérias é específica e depende de processos fisiológicos intracelular e extracelular, como também depende da espécie utilizada que influencia no tamanho da parede celular, tipo de enzimas e condições de cultivo. A eficiência de remoção geralmente é afetada pela concentração celular de microalgas e cianobactérias, pois maior biomassa fornece mais superfície celular, volumes e enzimas para adsorção, absorção e degradação do contaminante. Porém, se o volume de biomassa for elevado, as células agregam-se, levando a uma redução na área de adsorção efetiva, além disso aumenta a competição por nutrientes e problemas de auto sombreamento que restringem a capacidade de absorção e degradação dos HPAs (Chan, Luan, Wong, \& Tam, 2006).

Pesquisadores têm demonstrado que microorganismos como as cianófitas e as microalgas têm três maneiras diferentes de remover os hidrocarbonetos poliaromáticos do ambiente; 1) adsorção de HPAs na superfície das células algais dependendo dos grupos ativos presentes nessas superfícies, 2) sorção e acumulação de HPAs dentro das células algais e 3) transformação 
de HPAs que depende das ações enzimáticas, sendo o terceiro método de remoção considerado o eficaz para remover a toxicidade dos HPAs no ambiente (Aldaby \& Mawad 2019; Mustafa, Bhatti, Maqbool, \& Iqbal, 2021).

Portanto, os mecanismos fisiológicos na ficorremediação são divididos em duas vias: extracelular e intracelular. Na extracelular, define-se o conceito de ficoadsorção, considerado um processo de retenção de substâncias solúveis que são depositadas na superfície celular por diferença de carga (eletroafinidade). A via intracelular compreende a ficosorção junto a ficoacumulação que é um processo metabolicamente ativo no qual as microalgas e cianobactérias absorvem os contaminantes que estão na superfície celular (realizam sorção), sendo armazenados e acumulados nas células internas. Por fim, a ficodegradação que consiste no uso de enzimas para degradar o composto original quebrando em moléculas mais simples (Figura 3).

Figura 3 - Ilustração das etapas dos mecanismos utilizados na ficorremediação por parte das microalgas e cianobactérias para remoção de HPAs em água.

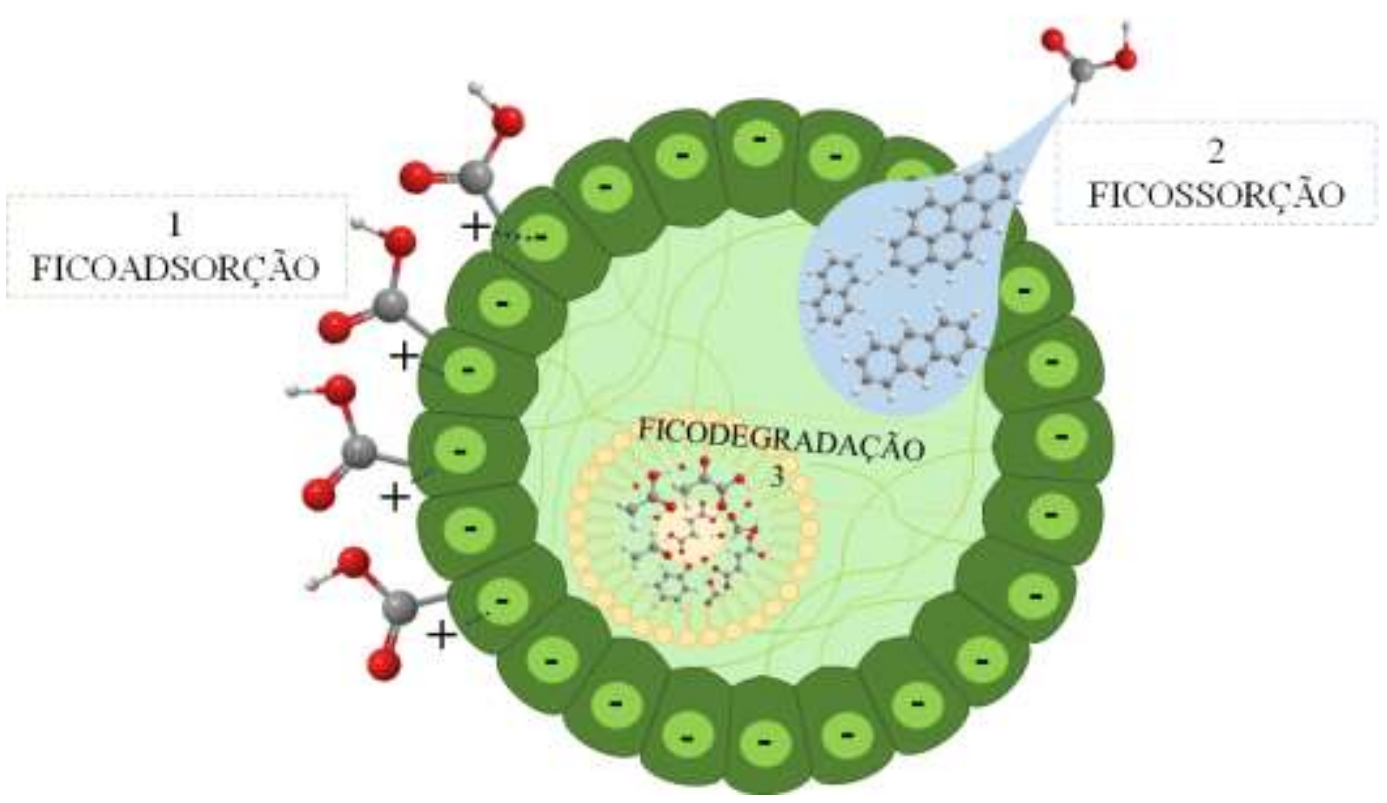

Fonte: Adaptado de Rempel et al. (2021).

\subsubsection{Ficoadsorção}

A ficoadsorção ocorre através das paredes celulares de diferentes espécies de microalgas, tendo associações com polímeros muito semelhantes a pectinas, proteínas e celuloses. Embora a parede celular das microalgas seja composta por carboidratos, uma matriz de fibrila, espaços intercelulares e polissacarídeos sulfatados, podem facilitar a ficoadsorção de contaminantes orgânicos na água (Nie et al., 2020). A parede celular é carregada negativamente por causa de seus diferentes grupos funcionais (amino, carboxila, hidroxila, sulfato, fosfato, fenol e sulfidrila), facilitando a ficoadsorção dos compostos orgânicos do petróleo. Este processo é caracterizado como extracelular, processo físico, e a eficácia da adsorção dos diferentes compostos varia de acordo com o contaminante e a espécie de microalga (Danouche, Ghachtouli \& Arroussi 2021).

Para a ficoadsorção, a diferença na hidrofobia e na estrutura dos grupos funcionais são fatores extremamente importantes. É preferível que o contaminante seja mais hidrofóbico do que hidrofílico e apresente uma carga oposta à das microalgas para garantir melhores eficiências no processo. Os compostos que apresentam propriedades hidrofílicas são aniônicos (carregados negativamente) e têm baixos valores de afinidade de ficoadsorção com as células microalgais devido às 
células também estarem carregadas negativamente. Já as moléculas lipofílicas, que são catiônicas, têm altos valores de afinidade de ficoadsorção com microalgas (Sutherland \& Ralph, 2019).

Alguns dos processos químicos que podem ocorrer na superfície da célula durante a ficoadsorção incluem reações de adsorção, reações de troca iônica com grupos funcionais, reações de complexação de superfície, quelação e microprecipitação (Rempel et al., 2021). Por ser um processo físico, a ficoadsorção ocorre independente do metabolismo, sendo relatado pelos pesquisadores Luo et al. (2014) que as células de microalgas mortas têm maior capacidade de ficoadsorção de HPAs do que as células vivas, onde apresentaram em seus experimentos eficiência de adsorção em $81 \%$ do Benzo (a) Pireno pelas células mortas da microalga Chlorella sp. Isto ocorre porque as células mortas apresentam ausência de proteção metabólica, o que impede o transporte de poluentes para o interior da célula, aumentando a permeabilidade da membrana celular. Este processo também é denominado de ficoadsorção passiva, por não existir interação metabólica direta com o contaminante (Luo et al., 2014).

García de Llasera et al. (2018) afirmam que a ficoadsorção é a primeira etapa utilizada pelas microalgas para remoção de HPAs nas primeiras 3 horas. Após este período, outros mecanismos são acionados, como a ficodegradação e ficoacumulação, para remoção completa dos hidrocarbonetos por parte das microalgas. Curiosamente, no caso das cianobactérias foi identificado por Bai et al. (2016) que a espécie Microcystis aeruginosa tanto adsorve contaminantes na superfície celular em até 24 horas, quanto libera substâncias poliméricas extracelulares (EPS) para a adsorção dos contaminantes em até 2 horas. A capacidade de ficoadsorção do fenantreno pela cianobactéria foi de $6,78 \mu \mathrm{g} \mathrm{mg}^{-1}$, comparado com EPS que foi de $12,31 \mu \mathrm{g} \mathrm{mg}^{-1}$ que ocorre devido a ligação conduzida por força eletrostática e interações hidrofóbicas. Após esta interação, são realizadas etapas seguintes denominadas de ficosorção e ficoacumulação, onde o fenantreno foi acumulado tanto nas células da cianobactéria quanto no EPS (Bai et al., 2016).

Figura 4 - Ilustração de como ocorre a ficoadsorção através da parede celular das microalgas e cianobactérias. A ficoadsorção também ocorre através das Substâncias Poliméricas Extracelulares (EPS) liberadas pelas cianobactérias.

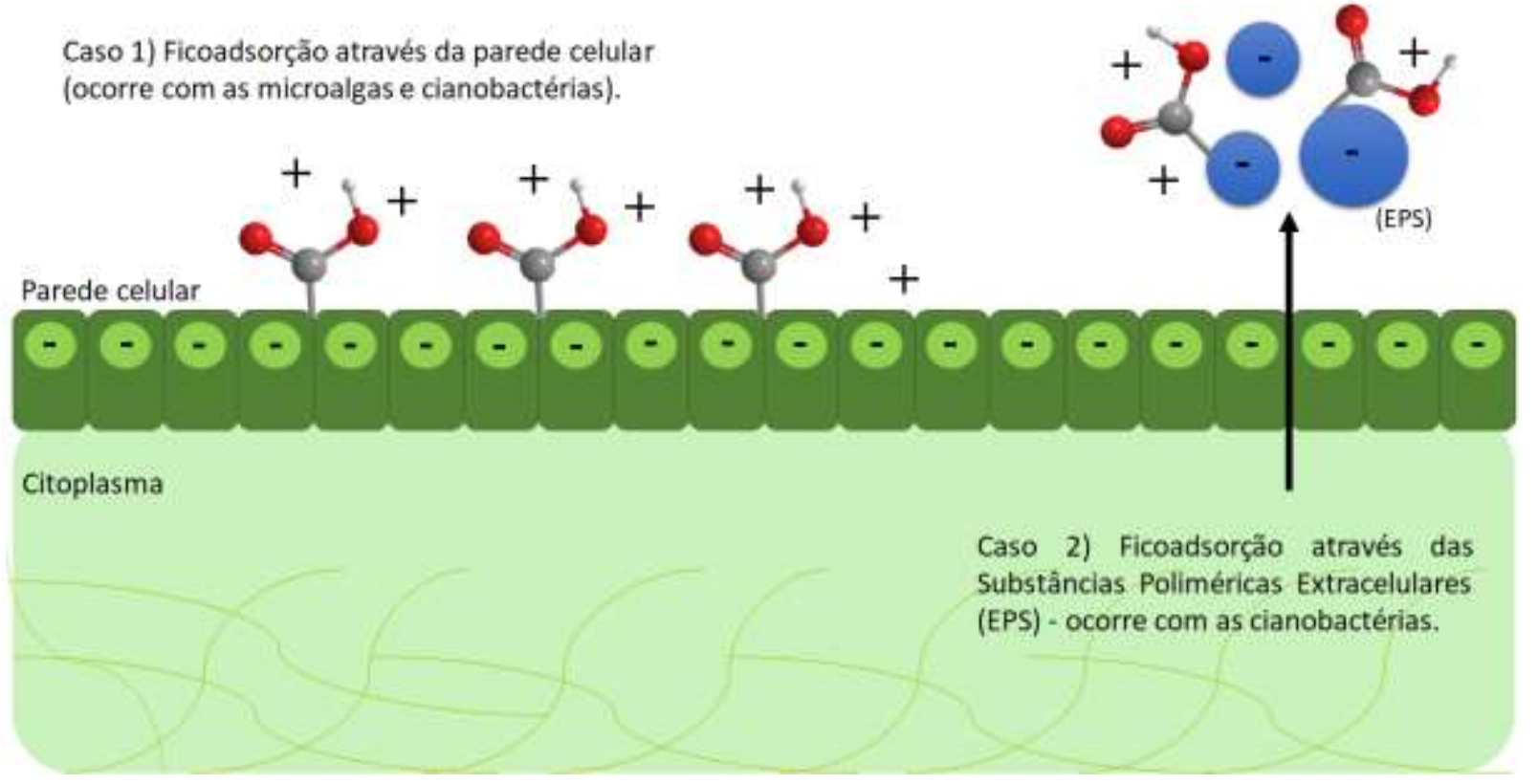

Fonte: Autores (2021). 


\subsubsection{Ficossorção e Ficoacumulação}

O processo de ficossorção envolve o uso de biomassa viva ou morta para remover contaminantes por interações físicas e químicas que levam à sua imobilização na biomassa. Todos os compostos inorgânicos e orgânicos que apresentam propriedades hidrofóbicas e hidrofílicas podem sofrer este processo. Considerando o caso da biomassa morta, a ficossorção segue um processo semelhante de ficoadsorção, onde envolve a retenção de contaminantes na parede celular da microalga ou cianobactéria, sendo este o processo dominante. Um mecanismo mais complexo foi observado para a ficossorção envolvendo biomassa viva, que para além da própria ficossorção, podem ocorrer processos simultâneos de ficoacumulação, transformação biológica e ficodegradação de compostos orgânicos, incluindo hidrocarbonetos alifáticos e aromáticos (Ofman, Skoczko, \& Włodarczyk-Makuła, 2021).

A ficossorção é considerada então um processo passivo, quando envolve biomassa morta, e um processo ativo, quando envolve etapas metabólicas em diferentes substratos que ocorrem no interior das células (Luo et al., 2014). Segundo Singh, Bauddh e Bux (2015) o processo de sorção é dividido em duas fases: a fase sólida que envolve o sorvente biológico (biomassa) e a fase líquida que consiste em um solvente, geralmente a água, que possui um adsorbato dissolvido. O sorvente biológico (biomassa), entra no processo de ficossorção, onde inicialmente as microalgas e cianobactérias podem adsorver contaminantes orgânicos através da sua parede celular e posteriormente, absorver este contaminante, passando pela membrana plasmática (no caso das cianobactérias) e interagindo com o citoplasma (para microalgas e cianobactérias), que ocorre juntamente com a síntese metabólica de nutrientes presentes em suas células. (Singh, Bauddh \& Bux, 2015; Bai et al., 2016; Marques et al., 2021).

Após a ficossorção, os micropoluentes são transportados para as células internas sendo ficoacumulados. A ficoacumulação de micropoluentes por algas é considerada uma rota essencial para a remoção desses poluentes em água. Embora as microalgas possam resistir a contaminantes em baixas concentrações devido às suas propriedades de adaptação a ambientes com essas substâncias, a remoção de compostos orgânicos via ficoacumulação é aumentada quando as microalgas são pré adaptadas a meios com baixas concentrações de poluentes, assim a ficoacumulação pode ser uma etapa anterior à ficodegradação. A combinação dessas duas vias de remoção contribui consideravelmente para sua assimilação e remoção (Rempel et al., 2021).

A ficoacumulação de compostos orgânicos sintéticos por uma ampla variedade de espécies de microalgas tem sido demonstrada, assim mesmo a taxa ou magnitude da ficoacumulação de compostos tóxicos, o tamanho e morfologia das células das microalgas têm demonstrado desempenhar um papel fundamental nas atividades fisiológicas como na absorção de nutrientes, fotossíntese, respiração e regulação de produtos residuais. Embora a área de superfície maior das microalgas para o volume faz com que exibam uma melhor capacidade de ficossorção de metal consideravelmente comparada com as macroalgas (Lei, Hu, Wong, \& Tam, 2007). 
Figura 5 - Ilustração do funcionamento da ficosorção (adsorção através da parede celular e absorção através do citoplasma das microalgas e cianobactérias) e da ficoacumulação (acúmulo dos contaminantes nas mitocôndrias, lipídios, vacúolo e cloroplasto).

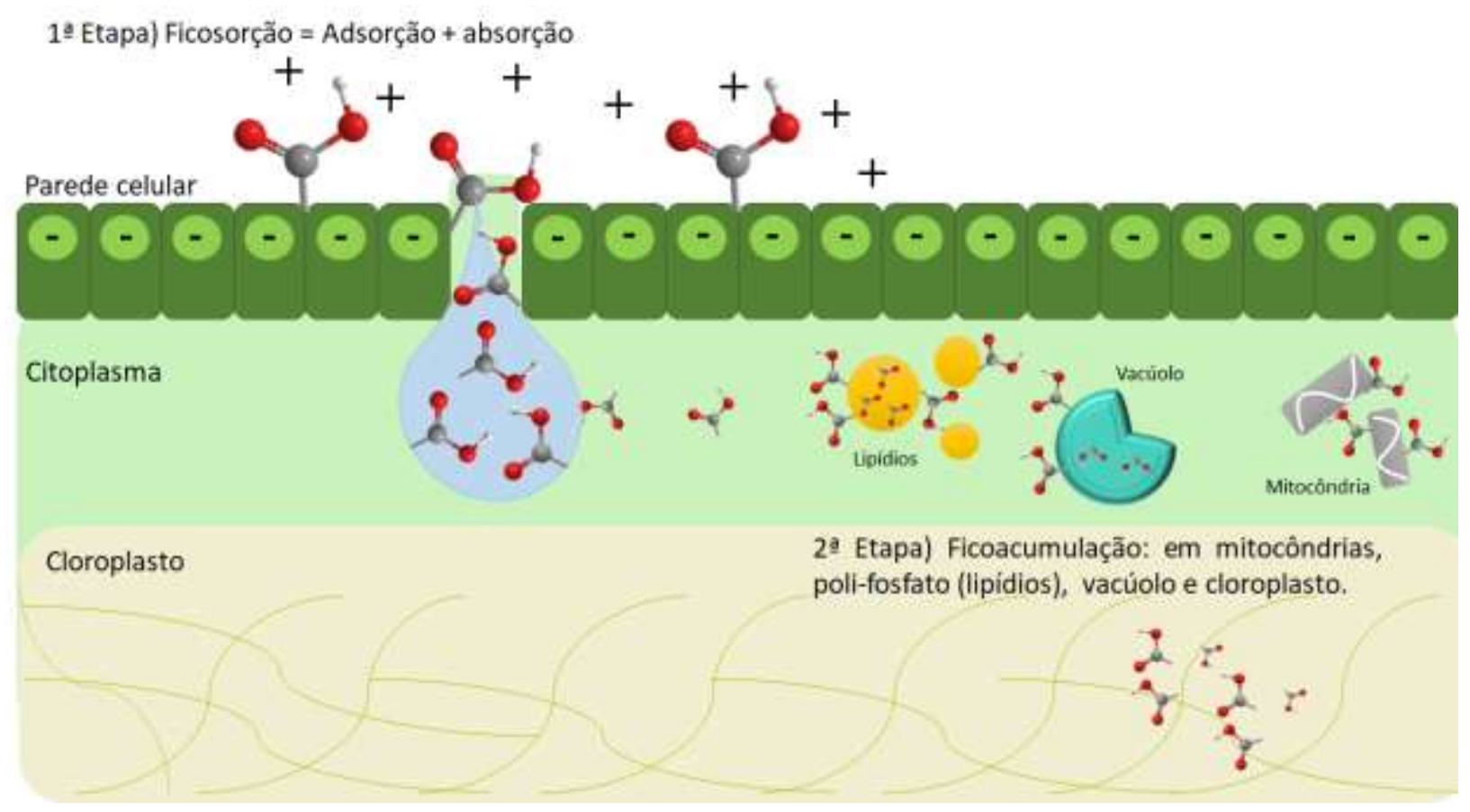

Fonte: Autores (2021).

\subsubsection{Ficodegradação}

Os HPAs apresentam recalcitrância à degradação microbiana aumentando diretamente com o peso molecular e o coeficiente de partição de água (log Kow) octanol. A principal trasformação destes compostos depois de um ataque bacteriano oxidativo é sua forma cis-di-hidrodióis. A oxidação destes compostos envolve a incorporação enzimática de oxigênio atmosférico no substrato; característicamente, produzem-se enzimas dioxigenases, que incorporam dois átomos de oxigênio no núcleo aromático. A dioxigenase que catalisa essas reações iniciais é um sistema enzimático multicomponente, a oxidação do anel inicial é geralmente a etapa limitadora da taxa na reação da ficodegradação dos HPAs (Juhasz \& Naidu, 2000). Assim, mesmo as estratégias de degradação iniciam o ataque enzimático aos anéis aromáticos pelo oxigênio, por outro lado, as vias orto e meta envolvem clivagem do anel, o que resulta na produção de ácidos succínico, fumárico, pirúvico, acético e aldeídos (Ghasemi, Rasoul-Amini, \& Fotooh-Abadi, 2011).

Entre os diferentes mecanismos de remoção destes compostos, a ficodegradação é uma estratégia de tratamento eficaz para remover compostos de locais poluídos por meio de microorganismos que podem decompor ou biotransformar essas substâncias orgânicas em um produto menos tóxico (Aldaby \& Mawad 2019). Por meio de seu metabolismo, as microalgas quebram cataliticamente estes compostos; elas possuem em suas células um complexo enzimático que atua em duas fases distintas. A primeira fase é caracterizada por um ataque inicial às substâncias, transformando assim os compostos mais hidrofílicos, em geral este processo é caracterizado por reações de hidrólise, redução ou oxidação de grupos hidroxila. As reações mais comuns apresentadas são carboxilação, hidrogenação e clivagem do anel. Porém, a enzima responsável por esse processo inicial é o citocromo P450. Na segunda fase, a enzima glutationa protege as células contra os processos de oxidação, resultando em morte celular, esses catalisadores são desenvolvidos com a junção entre compostos eletrofílicos e glutationa (Rempel et al., 2021). 
Figura 6 - Mecanismos de transformação do composto Benzo [a] pireno reagindo com a enzima epoxi hidrolase e o citocromo CYP 450 finalizando com o produto da reação da glutationa.

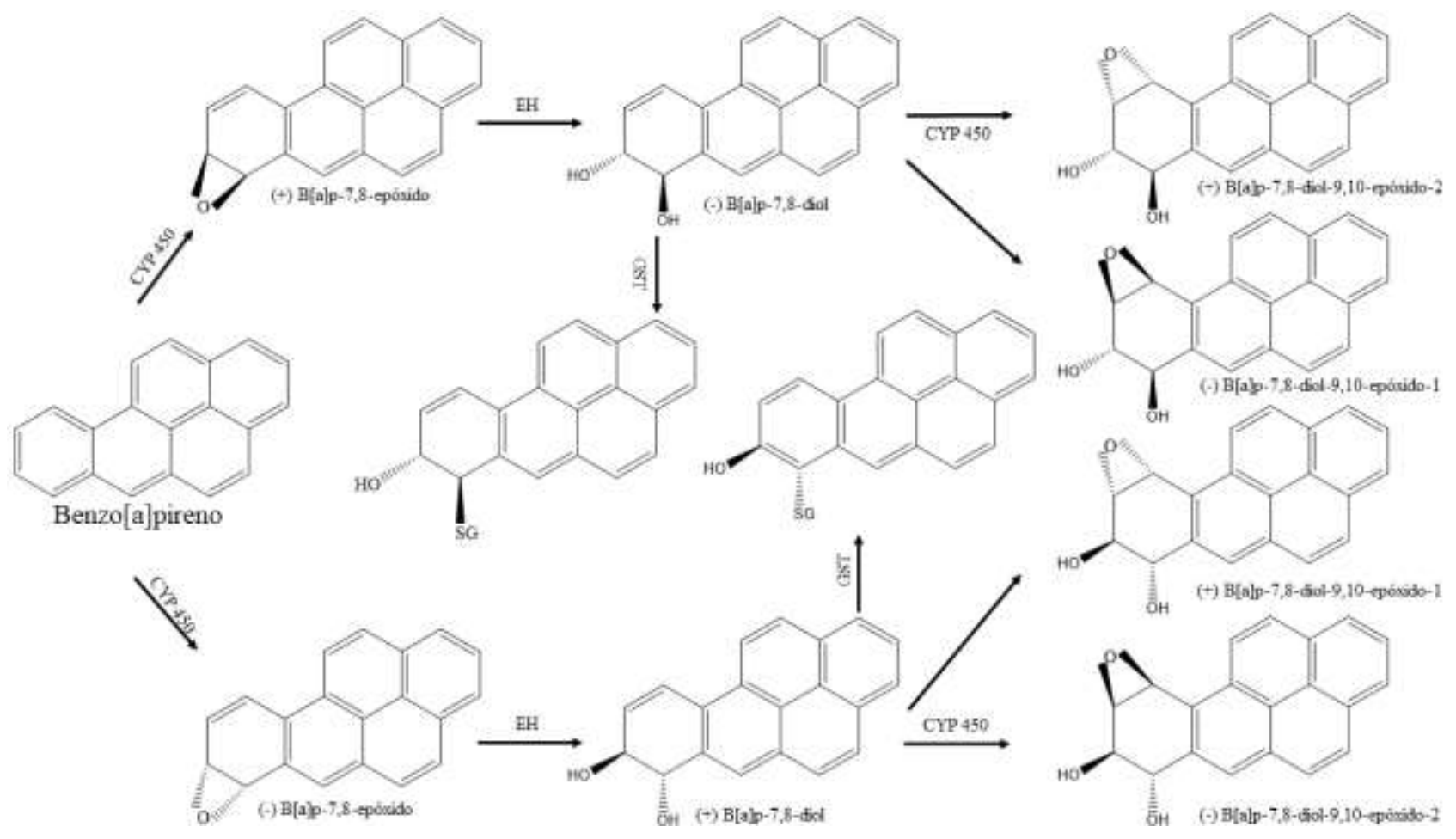

Fonte: Adaptado de Miranda (2008); Vázquez-Gómez, Rubio-Lightbourn, e Espinosa-Aguirre (2016).

\subsection{Biorrefinaria e bioeconomia circular}

Uma bioeconomia circular propõe o uso eficiente da biomassa, que incluem resíduos e fluxos laterais para a produção sustentável de produtos de alto valor agregado, como alimentos, fertilizantes, rações e bioenergia.

Este conceito se baseia na ideia de reciclagem, reutilização e remanufatura para geração de bioprodutos úteis para a sociedade. Portanto, a bioeconomia circular pode ser considerada como uma economia de baixo carbono, uma vez que apresenta potencial para o desenvolvimento de um ambiente mais sustentável (Leong et al., 2021).

Para a realização de uma bioeconomia, o processamento da biomassa em uma biorrefinaria pode ser considerado. A ideia de uma biorrefinaria é semelhante à de uma refinaria de petróleo tradicional, na qual todos os compostos disponíveis na biomassa são convertidos em uma gama de produtos comercializáveis e de energia, tendo como propósito primordial tornar o processo o mais sustentável possível e reduzir os custos de produção (Kumar e Goud, 2021; Deprá et al., 2018; Silva, Barbera \& Bertucco, 2019).

\subsubsection{Biorrefinaria de microalgas e cianobactérias}

As microalgas têm chamado atenção como fonte sustentável de matéria prima para biorrefinaria por apresentar diversas vantagens quando comparadas a culturas tradicionais (soja, milho e cana de açúcar) como i) maior fixação de dióxido de carbono, ii) taxa de crescimento de biomassa elevada, iii) cultivo em áreas não agricultáveis (Banu, Kavitha, Gunasekaran \& Kumar, 2020).

A biorrefinaria de microalgas envolve a combinação de tecnologias de colheita, fracionamento, hidrólise da biomassa e conversão em bioprodutos, visando minimizar a entrada de energia e a geração de resíduos e maximizar a produção de bioprodutos (Sankaran, Show, Nagarajan \& Chang, 2018). 
Essa abordagem aliada ao tratamento da água produzida pode formar a base de uma tecnologia econômica e sustentável, removendo nutrientes presentes nessa água, como o nitrogênio e fósforo, de uma forma ecologicamente mais segura com os benefícios adicionais da produção de bioprodutos a partir da biomassa produzida pelas mesmas durante o seu cultivo (Bolatkhan et al., 2020; Rahman, Agrawal, Nawaz, Pan \& Selvaratnam, 2020).

A biomassa de microalgas é composta por proteínas, lipídios, carboidratos, pigmentos e outros compostos bioativos que podem ser a matéria-prima para diversos produtos de valor comercial e industrial como demonstrado na figura 7 (Bastiaens, Van Roy, Thomassen \& Elst, 2017).

Os lipídios e carboidratos extraídos da biomassa das microalgas podem ser utilizados como matéria-prima para a produção de biocombustíveis, como o biodiesel e o bioetanol (Taher, Al-Zuhair, Al-Marzouqi, Haik \& Farid, 2014; Chen et al., 2013). Além disso, as microalgas podem ser comercializadas como suplementos alimentares devido às propriedades antioxidantes, antitumorais, anti-inflamatórias e neuroprotetoras associadas aos compostos bioativos presentes em sua biomassa. Como exemplo, temos os ácidos graxos de ômega 3 e ômega 6 e os pigmentos, que podem também ser utilizados nas indústrias farmacêuticas para tratar algumas doenças e como corantes naturais (Chew et al., 2017; Morales-Jiménez, Gouveia, Yáñez-Fernández, Castro-Muñoz \& Barragán-Huerta, 2020).

Figura 7 - Diagrama de blocos dos diferentes componentes da biomassa microalgal e bioprodutos derivados.

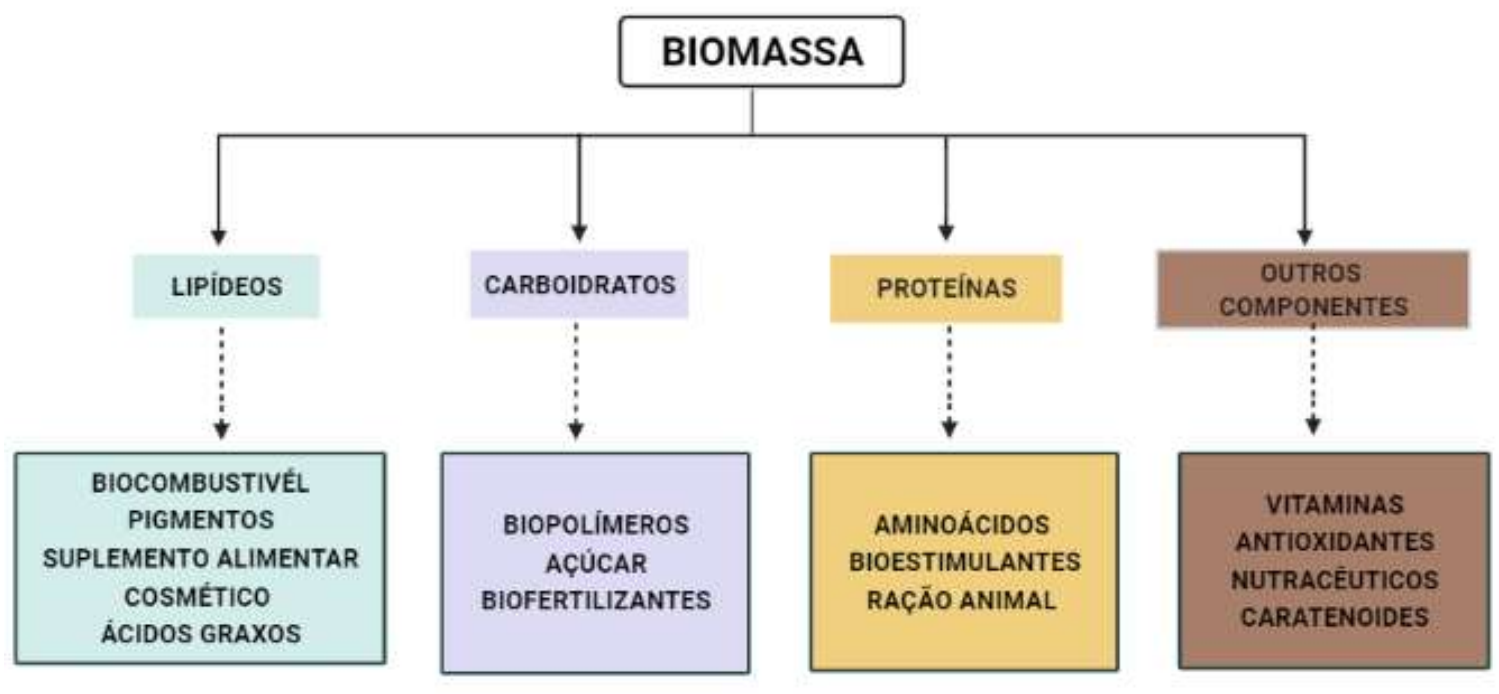

Fonte: Autores (2021).

Assim como as microalgas, as cianobactérias são capazes de produzir uma ampla gama de bioprodutos a partir da biomassa produzida. (Fasahati, Wu \& Maravelias, 2019).

A transformação da biomassa de cianobactérias em combustível tem se tornado uma fonte atrativa por ser um potencial substituto dos combustíveis fósseis (Singh, Chaudhary, Mani \& Dhar, 2016). Os carboidratos e lipídios presentes na biomassa de cianobactérias podem ser extraídos e convertidos em biocombustíveis, como o bioetanol e o biodiesel. Além do mais, as cianobactérias possuem o pigmento ficocianina, que apresenta propriedades nutracêuticas, podendo ser aplicado na produção de alimentos (da Fontoura Prates, Radmann, Duarte, de Morais \& Costa, 2018). A biomassa também pode ser utilizada como matéria-prima para produção de antioxidantes, agentes corantes, produtos farmacêuticos e compostos bioativos (Parmar, Singh, Pandey, Gnansounou \& Madamwar, 2011). 


\subsection{Bioprodutos para indústria no ambito da bioeconomia circular}

\subsubsection{Biopolímeros}

Os plásticos tradicionais à base de petróleo se tornaram os materiais mais utilizados devido às suas características, sendo inertes, versáteis e duráveis. No entanto, eles apresentam propriedades negativas, como emissões de $\mathrm{CO}_{2}$ da incineração, substâncias tóxicas, acumulação no meio ambiente e recalcitrância à biodegradação. Dessa forma, a busca por uma alternativa se tornou essencial para reduzir a dependência de recursos não renováveis (Singh, Sharma, Mallick e Mala, 2017; Kamravamanesh, Lackner \& Herwig, 2018).

Os polihidroxialcanoatos (PHAs) são bioplásticos promissores em razão das suas propriedades materiais serem similares às do polipropileno e por serem processados de forma semelhante ao mesmo, além de poderem ser degradados pelos microrganismos presentes no meio ambiente, permitindo, facilmente, compostagem do material residual (Costa, Miranda, de Morais, Costa \& Druzian, 2019).

As microalgas e cianobactérias são capazes de produzir PHA a partir da sua biomassa. Ademais, a produção de PHA a partir de $\mathrm{CO}_{2}$ capturado pelas mesmas contribui para um processo neutro em termos de emissão de carbono para a fabricação de plásticos biodegradáveis (Bhati \& Mallick, 2016).

O PHA é composto por monômeros e grupos funcionais, tais como halogênios, fenóxi, acetoxi, fenil, ciano e grupos epóxi. Os métodos de extração podem interferir de forma significativa na composição monomérica e, consequentemente, nas propriedades do PHA. A extração envolve diferentes técnicas, tais como a desestabilização, ruptura celular, separação do meio de cultura da biomassa, recuperação do biopolímero e purificação, que visam a remoção adequada do biopolímero acumulado no meio intracelular. Os métodos usados para extração de PHA abarcam a utilização de solventes orgânicos, fluidos supercríticos, digestão biológica por meio de enzimas, aplicação de métodos mecânicos e químicos combinados (Costa et al., 2018).

García et al. (2021) analisaram a produção de PHA a partir da microalga Scenedesmus sp., cultivada em dezesseis meios de cultura BG-11 sintético que diferiam entre si pelas condições de nutrientes, sendo estas limitações de nitrogênio, fósforo e ferro, suplementação com glicose e variação na salinidade. A presença de PHA foi detectada nas dezesseis experiências realizadas, com concentrações variando de 0,82 a 29,92\% (em termos de peso seco celular), sendo a maior concentração observada em meio com deficiência em fósforo, concentração normal de ferro, baixo nível de glicose e salinidade. O cultivo de Scenedesmus sp. em condições normais, isto é, sem deficiência de nutrientes, no meio BG-11 padrão acumulou 8,61\% de PHA. Além disso, eles observaram que a limitação de fósforo deve ser acompanhada da presença de ferro para se obter uma maior concentração do bioproduto. Quando a microalga analisada cresceu em um meio com a concentração normal de ferro e limitação de fósforo, a produção de PHA aumentou de 8,61 para 29,92\%, que foi a maior concentração obtida nos experimentos. Além disso, a interação entre glicose e nitrogênio foi considerada importante para o acúmulo de PHA.

Mendhulkar e Shetye (2017) realizaram a extração de PHA da espécie de cianobactéria Synechococcus elongates, cultivada em dois conjuntos de meio sintético ASN-III, sendo o primeiro deficiente em nitrogênio e contendo glicose, frutose, sacarose, glicerol e citrato como fontes de carbono, e o segundo deficiente em fosfato e contendo os mesmos componentes citados no primeiro conjunto, sendo ambos testados em condições mixotróficas. Como resultado, eles observaram que o maior rendimento de PHA foi obtido a partir de células cultivadas em meio deficiente em nitrogênio suplementado com sacarose como fonte de carbono, tanto em condições fotoautotróficas quanto em condições quimioheterotróficas. Entretanto, em meios deficientes em fosfato, os resultados variaram, sendo que em condições fotoautotróficas, o maior rendimento de PHA foi obtido das células cultivadas em meio suplementado com frutose como fonte de carbono, e em condições quimioheterotróficas o maior rendimento foi observado em meio suplementado com glicose como fonte de carbono. 
Shrivastav, Mishra e Mishra (2010) estudaram a cianobactéria Spirulina subsalsa para produção de PHA. As células foram cultivadas em meio ASN-III deficiente em nitrogênio e com uma concentração cinco vezes maior de $\mathrm{NaCl}$. A cultura de Spirulina subsalsa incubada em concentração aumentada de $\mathrm{NaCl}$ foi comparada com a cultura de Spirulina subsalsa incubada em condições normais. Quando a cultura foi incubada com o aumento do nível de $\mathrm{NaCl}$ no meio livre de nitrogênio, a cultura apresentou aumento da capacidade de síntese de PHA, que totalizou em 7,45\% p/p, enquanto que em condições normais a produção de PHA foi de 5,9\% p/p.

As microalgas e cianobactérias são microrganismos que podem crescer em níveis elevados de hidrocarbonetos e salinidade, como os encontrados na água produzida, reduzindo a matéria orgânica e os nutrientes inorgânicos presentes nessa água e incorporando esses compostos à biomassa produzida, que pode ser processada posteriormente e transformada em PHA (Ammar, Khadim \& Mohamed, 2018; Rueda et al., 2020).

\subsubsection{Biodiesel}

Nos últimos anos, a produção de combustível alternativo tem sido uma preocupação constante devido à diminuição das reservas de petróleo e os impactos ambientais causados pelos gases de exaustão dos combustíveis fósseis. O biodiesel pode ser uma alternativa adequada aos combustíveis não renováveis, visto que é um biocombustível de queima limpa, não tóxico e biodegradável. A produção de biodiesel através das microalgas tem se destacado em razão do seu rápido crescimento e da produtividade de lipídios a partir da biomassa produzida, além de reduzir as emissões de $\mathrm{CO}_{2}$ (Ashokkumar, Chen, Ngamcharussrivichai, Agila \& Ani, 2019; Uma, Gnanasekaran, Lakshmanan \& Dharmar, 2020). Tal como as microalgas, as cianobactérias são capazes de sintetizar e acumular grandes quantidades de lipídios, utilizados para produção de biodiesel (Hossain et al., 2020).

Em suma, a produção de biodiesel usando microalgas e cianobactérias consiste na produção de biomassa, colheita e secagem, que fornecem a matéria-prima necessária, além da extração e transesterificação de lipídios, que resultam na produção de biodiesel (Kwon \& Yeom, 2015). Os métodos para extrair os lipídios mais utilizados são o método Bligh e Dyer, Hara e Radin, Folch e Soxhlet. Na extração de lipídios, as células das microalgas devem ser rompidas para que o mesmo seja liberado e isso pode ser feito por meio de técnicas como moagem úmida, ultrassom, batimento de contas, microondas, autoclavagem em alta temperatura e pressão e interrupção osmótica por tratamento com cloreto de sódio (Taher, Al-Zuhair, Al-Marzouqi, Haik \& Farid, 2014).

Hopkins, Graham e Schuler (2019) realizaram o cultivo da microalga Dunaliella tertiolecta em uma ampla gama de condições salinas (30-210 $\mathrm{g}_{\text {TDS L}}{ }^{-1}$ ) em um meio a base de água produzida e determinaram a sua produtividade lipídica. Os resultados do estudo indicaram que a alta salinidade da água produzida não afetou o crescimento da microalga. Nas culturas de 30 e $60 \mathrm{~g}_{\text {TDS L }}^{-1}$, o conteúdo inicial de lipídios foi maior, com valores aproximados de $0,06 \mathrm{~g} \mathrm{~L}^{-1}$ no $8^{\circ}$ dia, diminuindo para $0,045 \mathrm{~g} \mathrm{~L}^{-1}$ do $8^{\circ}$ ao $15^{\circ}$ dia. Quando a cultura atingiu a fase estacionária após o $15^{\circ}$ dia, a concentração de lipídios aumentou até o final do experimento, atingindo o valor máximo de $0,070 \mathrm{~g} \mathrm{~L}^{-1}$. Para o cultivo em condições de 120,180 e $210 \mathrm{~g} \mathrm{TDS} \mathrm{L}^{-1}$, a concentração dos lipídios exibiram um aumento de 25-35\% após limitação de nitrato, até que a cultura entrou em fase estacionária no $17^{\circ}$ dia. O perfil dos ésteres metílicos de ácidos graxos apresentou uma prevalência de cadeias de carbono saturadas C16 (ácido palmítico) e insaturadas C18. Com o aumento da salinidade foi observada uma pequena diminuição de C16:0 e aumento de C18:3 (ácido linolênico). O menor valor de cetano calculado foi 59,3 e o maior 74, sendo todos os valores calculados maiores do que o padrão mínimo de biocombustível, que é 47. Eles concluíram que os perfis de ésteres metílicos de ácidos graxos obtidos são adequados para biodiesel.

Teo e Idris (2014) extraíram lipídios das microalgas Nannochloropsis sp. e Tetraselmis sp., transesterificando-os em biodiesel. Quatro métodos de extração por solvente foram usados: Hara e Radin (1978), que utiliza isopropanol e hexano; 
Folch (1957), que utiliza metanol e clorofórmio; Chen (1981), que utiliza metanol e diclorometano; e Bligh e Dyer (1959), que faz uso do metanol, clorofórmio e solução de sulfato de sódio. Esses métodos foram realizados usando métodos convencionais de aquecimento e irradiação de microondas. O maior rendimento lipídico para Tetraselmis sp. foi obtido pelo método de Hara e Radin (8,19\%), enquanto que para Nannochloropsis sp. o método de Folch resultou no maior rendimento lipídico $(8,47 \%)$. Cerca de 81-83\% do conteúdo total de ésteres metílicos de ácidos graxos em Tetraselmis sp. consiste em C16:0 (ácido palmítico) e C18:0 (ácido esteárico). O C16:0 (ácido palmítico) e o C18:0 (ácido esteárico) em Nannochloropsis sp. contribuem com cerca de 49-51\% do total de ésteres metílicos de ácidos graxos, enquanto que os outros 50\% consistem em ácido mirístico, elaídico, oleico, linolelaídico e linoléico. A ausência de ésteres metílicos com cadeias de carbono maiores que 19 carbonos assegura uma baixa viscosidade ao biodiesel.

Oliveira et al. (2018) investigaram três cepas de cianobactérias amazônicas, Cyanobium sp., Limnothrix sp. e Nostoc $s p$., cultivadas em dois meios de cultura (ASM-1 e BG-11), para avaliação da composição de ácidos graxos e para estimar os parâmetros de qualidade do biodiesel. A extração de lipídios foi realizada pelo método de Bligh e Dyer com modificações. Para realizar a esterificação, uma solução metanólica de hidróxido de sódio foi adicionada aos lipídios extraídos, assim como $\mathrm{BF}_{3}$ e heptano. Por fim, foi adicionada uma solução saturada de cloreto de sódio para separação de fases e a solução de heptano contendo os ésteres metílicos foi coletada para análise de cromatografia gasosa, no qual quinze tipos de ácidos graxos foram identificados, predominantemente compostos saturados, que representaram 47-86\% dos ácidos graxos produzidos pelas cianobactérias. A espécie Cyanobium sp. teve 86,22\% de produção de ácidos graxos saturados no meio BG-11. Foi observado em todas as cepas de cianobactérias um baixo teor de ácidos graxos poliinsaturados, o que indica a alta qualidade do óleo produzido por essas espécies. Ademais, os resultados obtidos mostraram que Limnothrix sp. produziu mais lipídios (9,12\% e $322 \mathrm{mgL}^{-1}$ ), embora essa cepa não tenha sido a maior produtora de biomassa. A mesma teve uma grande produção de C16:0 (ácido palmítico), o que garante uma boa qualidade do biodiesel.

Silva, Silva-Stenico, Fiore, de Castro e Da Rós (2014) otimizaram as condições de cultivo da cianobactéria Synechococcus sp. PCC7942 através da suplementação com $\mathrm{Na}_{2} \mathrm{CO}_{3}$ e alta intensidade de luz, a fim de avaliar seu conteúdo lipídico para geração de biodiesel. As células da cianobactéria foram cultivadas em meio BG-11 e quatro métodos para extração de lipídios foram empregados, sendo eles Bligh e Dyer, Folch (realizado em ultrassom), Folch (realizado em microondas) e 2-EE (2-etoxietanol). O método 2-EE foi o mais eficiente para extração lipídica, apresentando um teor de lipídios de 36,8 $\pm 1,2 \%$. Apesar disso, esse método se torna desvantajoso por necessitar de um solvente caro e difícil de recuperar. Em segundo lugar, o método de Folch por ultrassom apresentou um teor de 29,0 $\pm 2,1 \%$, com a vantagem do processo ser de fácil execução e do solvente usado ser barato. O método de Folch por radiação de microondas resultou em um teor de lipídios de 15,0 \pm 0,9\% e, por último, o método de Bligh e Dyer, com teor de 12,8 $\pm 4,3 \%$. Os ácidos graxos insaturados foram obtidos em maior quantidade (aproximadamente 79,8\%), sendo os principais tipos C18:2 (ácido linoléico), C18:1 (ácido oleico) e C16:0 (ácido palmítico). O biodiesel produzido pela cianobactéria apresentou número de cetano de 51,3 e valor de iodo de $97 \mathrm{~g} \mathrm{I}_{2} 100 \mathrm{~g}^{-1}$, estando ambos os parâmetros dentro dos limites europeu e brasileiro (no caso do número de cetano). Dessa forma, a matéria-prima lipídica da cianobactéria analisada é boa para a produção de biocombustíveis.

Tal qual observado para a produção de PHA, há poucos estudos que demonstram a capacidade microalgal de produção lipídica e geração de biodiesel tendo como meio de cultivo a água produzida. No entanto, é sabido que a composição química complexa da água produzida pode facilitar o crescimento de microalgas e cianobactérias, assim como a produção de lipídios (Rahman et al., 2020). 


\section{Considerações Finais}

A partir da presente revisão foi possível apresentar os principais avanços sobre o uso de microalgas e cianobactérias para ficorremediação de hidrocarbonetos policíclicos aromáticos (HPAs) presentes em água produzida do petróleo e os mecanismos pelos quais se dá essa técnica. Os principais mecanismos apresentados, a ficoadsorção, ficossorção e ficodegradação, utilizados pelas cianobactérias e microalgas auxiliam no processo de tratamento da água produzida quanto a remoção de hidrocarbonetos policíclicos aromáticos. Do aspecto da bioeconomia circular, a utilização da água produzida é uma importante fonte de água e nutrientes para o cultivo de microalgas e cianobactérias, sendo um método eficiente e sustentável para a remoção de HPAs, além da biomassa gerada ter diversas possibilidades de aplicação, considerando o cenário de uma biorrefinaria de microalgas.

O teor de lipídios e carboidratos desses microrganismos os tornam uma matéria-prima em potencial para produção de biocombustíveis e biopolímeros. No entanto, mais estudos precisam ser realizados para otimizar a viabilidade da geração desses bioprodutos utilizando como meio de cultivo a água produzida de petróleo.

Nesta revisão foram apresentados os principais avanços sobre o uso de microalgas e cianobactérias para ficorremediação de HPAs. Os principais mecanismos envolvidos na ficorremediação foram pioneiramente conceituados e apresentados o que poderá ajudar e dar suporte a pesquisas futuras sobre ficorremediação em diferentes efluentes industriais. $\mathrm{O}$ modelo de biorrefinaria no âmbito da bioeconomia circular foi apresentado como eficiente e sustentável para a remoção de HPAs, sendo este modelo promissor para o futuro das atividades petrolíferas. Os bioprodutos de alto valor agregado gerado após a ficorremediação foram devidamente apresentados e discutidos quanto às suas diversas possibilidades de aplicação.

\section{Agradecimentos}

Os autores agradecem à Agência Nacional do Petróleo, Gás Natural e Biocombustíveis (ANP), ao PRH-36 e à FINEP pelo apoio à pesquisa. Agradecemos ao Programa de Pós-Graduação em Geoquímica: Petróleo e Meio ambiente (POSPETRO/IGEO/UFBA), ao Programa de Pós-Graduação em Engenharia Industrial (PEI/EPOLI/UFBA) e ao Programa de Pós-Graduação em Desenvolvimento Regional e Urbano (PPDRU/UNIFACS) pelo apoio ao desenvolvimento das pesquisas que são realizadas na Universidade Federal da Bahia e Universidade Salvador.

\section{Referências}

Alam, F., Mobin, S., \& Chowdhury, H. (2015). Third generation biofuel from algae. Procedia Engineering, 105, $763-768$.

Alberts, B., Johnson, A., Lewis, J., Morgan, D., Raff, M., Roberts, K. \& Hunt, T. (2002). Biologia molecular da célula. Artmed Editora.

Aldaby, E. S. E., \& Mawad, A. M. M. (2019). Pyrene biodegradation capability of two different microalgal strains. Global Nest Journal, 21(3), 290-295. https://doi.org/10.30955/gnj.002767

Al-Ghouti, M. A., Al-Kaabi, M. A., Ashfaq, M. Y., \& Da'na, D. A. (2019). Produced water characteristics, treatment and reuse: A review. Journal of Water Process Engineering, 28, 222-239.

Amaral, M. S., Loures, C. C. A., Naves, F. L., Baeta, B. E. L., Silva, M. B., \& Prata, A. M. R. (2020). Evaluation of cell growth performance of microalgae Chlorella minutissima using an internal light integrated photobioreactor. Journal of Environmental Chemical Engineering, 8(5), 104200.

Ammar, S. H., Khadim, H. J., \& Mohamed, A. I. (2018). Cultivation of Nannochloropsis oculata and Isochrysis galbana microalgae in produced water for bioremediation and biomass production. Environmental Technology \& Innovation, 10, 132-142.

Andrade, D. S., \& Colozzi Filho, A. (2014). Microalgas de águas continentais.

ANP, Agência Nacional do Petróleo, Gás Natural e Biocombustíveis (2020). Dados estatísticos. <https://www.gov.br/anp/pt-br/centrais-de-conteudo/dadosestatisticos>

Ashokkumar, V., Chen, W. H., Ngamcharussrivichai, C., Agila, E., \& Ani, F. N. (2019). Potential of sustainable bioenergy production from Synechocystis sp. cultivated in wastewater at large scale-a low cost biorefinery approach. Energy Conversion and Management, 186, 188-199. 
Bai, L. Xu, H. Wang, C. Deng, J. Jiang, H. (2016). Extracellular polymeric substances facilitate the biosorption of phenanthrene on cyanobacteria Microcystis aeruginosa. Chemosphere. 162, $172-180$.

Banu, J. R., Kavitha, S., Gunasekaran, M., \& Kumar, G. (2020). Microalgae based biorefinery promoting circular bioeconomy-techno economic and life-cycle analysis. Bioresource technology, 302, 122822.

Bastiaens, L., Van Roy, S., Thomassen, G., \& Elst, K. (2017). Biorefinery of algae: Technical and economic considerations. In Microalgae-based biofuels and bioproducts (pp. 327-345). Woodhead Publishing.

Bezerra, B. G. P., da Silva Oliveira, I. K., da Costa, V. A., da Silva, D. R., \& Pergher, S. B. C. (2016). Remoção de metais tóxicos de água produzida empregando zeolita.

Bhati, R., \& Mallick, N. (2016). Carbon dioxide and poultry waste utilization for production of polyhydroxyalkanoate biopolymers by Nostoc muscorum Agardh: a sustainable approach. Journal of applied phycology, 28(1), 161-168.

Bolatkhan, K., Sadvakasova, A. K., Zayadan, B. K., Kakimova, A. B., Sarsekeyeva, F. K., Kossalbayev, B. D., Allakhverdiev, S. I. (2020). Prospects for the creation of a waste-free technology for wastewater treatment and utilization of carbon dioxide based on cyanobacteria for biodiesel production. Journal of Biotechnology.

Bozlaker, A., Muezzinoglu, A., \& Odabasi, M. (2008). Atmospheric concentrations, dry deposition and air-soil exchange of polycyclic aromatic hydrocarbons (PAHs) in an industrial region in Turkey. Journal of Hazardous Materials, 153(3), 1093-1102.

Brasil. Conselho Nacional de Meio Ambiente. (2007) Resolução no 393 de 8 de agosto 2007. Dispõe sobre o descarte contínuo de água de processo ou de produção em plataformas marítimas de petróleo e gás natural, e dá outras providências. Diário Oficial da União, Brasília, DF, 9 de agosto de 2007.

Chan, S. M. N., Luan, T., Wong, M. H., \& Tam, N. F. Y. (2006). Removal and biodegradation of polycyclic aromatic hydrocarbons by Selenastrum capricornutum. Environmental Toxicology and Chemistry, 25(7), 1772-1779. https://doi.org/10.1897/05-354R.1

Chen, C. Y., Zhao, X. Q., Yen, H. W., Ho, S. H., Cheng, C. L., Lee, D. J., \& Chang, J. S. (2013). Microalgae-based carbohydrates for biofuel production. Biochemical Engineering Journal, 78, 1-10.

Chen, F. (1996). High cell density culture of microalgae in heterotrophic growth. Trends in biotechnology, 14(11), 421-426.

Chew, K. W., Yap, J. Y., Show, P. L., Suan, N. H., Juan, J. C., Ling, T. C., Lee, D. J., \& Chang, J. S. (2017). Microalgae biorefinery: high value products perspectives. Bioresource technology, 229, 53-62.

Chisti, Y. (2007). Biodiesel from microalgae. Biotechnology advances, 25(3), 294-306.

Chu, F., Chu, P., Cai, P., Li, W., Lam, P. K. S. \& Zeng, R. J. (2013). Phosphorus plays an important role in enhancing biodie sel productivity of Chlorella vulgaris under nitrogen deficiency. Bioresource Technology, 134, 341-346.

Collins, L., Alvarez, D., \& Chauhan, A. (2014). Phycoremediation Coupled with Generation of Value-Added Products. In Microbial Biodegradation and Bioremediation (pp. 341-387). Elsevier.

Costa, S. S., Miranda, A. L., de Jesus Assis, D., Souza, C. O., de Morais, M. G., Costa, J. A. V., \& Druzian, J. I. (2018). Efficacy of Spirulina sp. polyhydroxyalkanoates extraction methods and influence on polymer properties and composition. Algal research, 33, 231-238.

Costa, S. S., Miranda, A. L., de Morais, M. G., Costa, J. A. V., \& Druzian, J. I. (2019). Microalgae as source of polyhydroxyalkanoates (PHAs)—A review. International journal of biological macromolecules, 131, 536-547.

da Fontoura Prates, D., Radmann, E. M., Duarte, J. H., de Morais, M. G., \& Costa, J. A. V. (2018). Spirulina cultivated under different light emitting diodes: Enhanced cell growth and phycocyanin production. Bioresource technology, 256, 38-43.

Danouche, M., Ghachtouli, N., \& Arroussi, H. (2021). Phycoremediation mechanisms of heavy metals using living green microalgae_physicochemical and molecular approaches for enhancing selectivity and removal capacity. Heliyon 7. https://doi.org/10.1016/j.heliyon.2021.e07609

Das, P., AbdulQuadir, M., Thaher, M., Khan, S., Chaudhary, A. K., Alghasal, G., \& Al-Jabri, H. M. S. (2019). Microalgal bioremediation of petroleumderived low salinity and low pH produced water. Journal of Applied Phycology, 31(1), 435-444.

de Farias Silva, C. E., Barbera, E., \& Bertucco, A. (2019). Biorefinery as a promising approach to promote ethanol industry from microalgae and cyanobacteria. In Bioethanol production from food crops (pp. 343-359). Academic Press.

de Oliveira, D. T., Vasconcelos, C. T., Feitosa, A. M. T., Aboim, J. B., de Oliveira, A. D. N., Xavier, L. P., ... \& do Nascimento, L. A. S. (2018). Lipid profile analysis of three new Amazonian cyanobacteria as potential sources of biodiesel. Fuel, 234, 785-788.

Deprá, M. C., dos Santos, A. M., Severo, I. A., Santos, A. B., Zepka, L. Q., \& Jacob-Lopes, E. (2018). Microalgal biorefineries for bioenergy production: can we move from concept to industrial reality?.BioEnergy Research, 11(4), 727-747.

Deviram, G., Mathimani, T., Anto, S., Ahamed, T. S., Ananth, D. A., \& Pugazhendhi, A. (2020). Applications of microalgal and cyanobacterial biomass on a way to safe, cleaner and a sustainable environment. Journal of Cleaner Production, 253, 119770.

Di Caprio, F., Altimari, P., Iaquaniello, G., Toro, L., \& Pagnanelli, F. (2019). Heterotrophic cultivation of T. obliquus under non-axenic conditions by uncoupled supply of nitrogen and glucose. Biochemical Engineering Journal, 145, 127-136.

Dos Santos, A. M., Vieira, K. R., Zepka, L. Q., \& Jacob-Lopes, E. (2019). Environmental applications of microalgae/cyanobacteria. In New and Future Developments in Microbial Biotechnology and Bioengineering (pp. 47-62). Elsevier. 
Douben, P. E. (Ed.). (2003). PAHs: an ecotoxicological perspective. John Wiley \& Sons.

Dyhrman, S. T. (2016). Nutrients and Their Acquisition: Phosphorus Physiology in Microalgae. Springer International Publishing, $155-183$.

El-Sheekh, M. M., \& Hamouda, R. A. (2014). Biodegradation of crude oil by some cyanobacteria under heterotrophic conditions. Desalination and Water Treatment, 52(7-9), 1448-1454.

Erbland, P., Caron, S., Peterson, M., \& Alyokhin, A. (2020). Design and performance of a low-cost, automated, large-scale photobioreactor for microalgae production. Aquacultural Engineering, 90, 1.

Estrela, C. (2018). Metodologia Científica: Ciência, Ensino, Pesquisa. Editora Artes Médicas.

Fasahati, P., Wu, W., \& Maravelias, C. T. (2019). Process synthesis and economic analysis of cyanobacteria biorefineries: A superstructure-based approach. Applied Energy, 253, 113625.

Fernández, F. G. A., Fernández-Sevilla, J. M., Moya, B. L., \& Grima, E. M. (2020). Microalgae production systems. In Handbook of Microalgae-Based Processes and Products (pp. 127-163). Academic Press.

Fernández, F. G. A., Reis, A., Wijffels, R. H., Barbosa, M., Verdelho, V., Lhamas, B. (2020). The role of microalgae in the bioeconomy. Nova biotecnologia. https://doi.org/10.1016/j.nbt.2020.11.011

Ferraro, A., Massini, G., Miritana, V. M., Panico, A., Pontoni, L., Race, M., Rosa, S., Signorini, A., Fabbricino, M., \& Pirozzi, F. (2021). Bioaugmentation strategy to enhance polycyclic aromatic hydrocarbons anaerobic biodegradation in contaminated soils. Chemosphere, 275 , 130091. https://doi.org/10.1016/j.chemosphere.2021.130091

García de Llasera, M. P. Santiago, M. L. Flores, E. J. L. Toris, D. N. B. Herrera, M. R. C. (2018). Mini-bioreactors with immobilized microalgae for the removal of benzo(a)anthracene and benzo(a)pyrene from water. Ecological Engineering. 121, $89-98$.

García, G., Sosa-Hernández, J. E., Rodas-Zuluaga, L. I., Castillo-Zacarías, C., Iqbal, H., \& Parra-Saldívar, R. (2021). Accumulation of PHA in the microalgae Scenedesmus sp. under nutrient-deficient conditions. Polymers, 13(1), 131.

Ghasemi, Y., Rasoul-Amini, S., \& Fotooh-Abadi, E. (2011). The biotransformation, biodegradation, and bioremediation of organic compounds by microalgae. Journal of Phycology, 47(5), 969-980. https://doi.org/10.1111/j.1529-8817.2011.01051.x

Hammed, A. M., Prajapati, S. K., Simsek, S., \& Simsek, H. (2016). Growth regime and environmental remediation of microalgae. Algae, 31(3), 189-204.

Holzinger, A., \& Karsten, U. (2013). Desiccation stress and tolerance in green algae: consequences for ultrastructure, physiological and molecular mechanisms. Frontiers in plant science, $4,327$.

Hopkins, T. C., Graham, E. J. S., \& Schuler, A. J. (2019). Biomass and lipid productivity of Dunaliella tertiolecta in a produced water-based medium over a range of salinities. Journal of Applied Phycology, 31(6), 3349-3358.

Hossain, M. F., Ratnayake, R. R., Mahbub, S., Kumara, K. W., \& Magana-Arachchi, D. N. (2020). Identification and culturing of cyanobacteria isolated from freshwater bodies of Sri Lanka for biodiesel production. Saudi Journal of Biological Sciences, 27(6), 1514-1520.

Igunnu, E. T., \& Chen, G. Z. (2014). Produced water treatment technologies. International Journal of Low-Carbon Technologies, 9(3), $157-177$.

Jeyakumar, B., Asha, D., Varalakshmi, P., \& Kathiresan, S. (2020). Nitrogen repletion favors cellular metabolism and improves eicosapentaenoic acid production in the marine microalga Isochrysis sp. CASA CC 101. Algal Research, 47, 101877.

Ji, M., Abou-Shanab, R. A.I., Kim, S., Salama, E., Lee, S., Kabra, A. N., Lee, Y., Hong, S., Jeon, B. (2013). Cultivation of microalgae species in tertiary municipal wastewater supplemented with $\mathrm{CO} 2$ for nutrient removal and biomass production. Ecological Engineering, $58,142-148$.

Jiménez, S., Micó, M. M., Arnaldos, M., Medina, F., \& Contreras, S. (2018). State of the art of produced water treatment. Chemosphere, 192, 186-208.

Johnson, T. J., Katuwal, S., Anderson, G. A., Gu, L., Zhou, R., \& Gibbons, W. R. (2018). Photobioreactor cultivation strategies for microalgae and cyanobacteria. Biotechnology progress, 34(4), 811-827.

Juhasz, A. L., \& Naidu, R. (2000). Bioremediation of high molecular weight polycyclic aromatic hydrocarbons: A review of the microbial degradation of benzo[a]pyrene. International Biodeterioration and Biodegradation, 45(1-2), 57-88. https://doi.org/10.1016/S0964-8305(00)00052-4

Kabyl, A., Yang, M., Abbassi, R., \& Li, S. (2020). A risk-based approach to produced water management in offshore oil and gas operations. Process safety and Environmental protection, 139, 341-361.

Kamravamanesh, D., Lackner, M., \& Herwig, C. (2018). Bioprocess engineering aspects of sustainable polyhydroxyalkanoate production in cyanobacteria. Bioengineering, 5(4), 111

Khola, G., \& Ghazala, B. (2012). Biodiesel production from algae. Pak. J. Bot, 44(1), 379-381.

Kumar, D., \& Goud, V. V. (2021). 12 Lifecycle assessment of microalgal biorefinery. Algal Biorefinery: Developments, Challenges and Opportunities, 293.

Kwon, M. H., \& Yeom, S. H. (2015). Optimization of one-step extraction and transesterification process for biodiesel production from the marine microalga Nannochloropsis sp. KMMCC 290 cultivated in a raceway pond. Biotechnology and Bioprocess Engineering, 20(2), $276-283$.

Lam, M. K., Yussof, M. I., Uemura, Y., Lim, J. W., Khoo, C. G., Lee, K. T. \& Ong, H.C. (2017). Cultivation of Chlorella vulgaris using nutrients source from domestic wastewater for biodiesel production: Growth condition and kinetic studies. Renewable Energy, 103, $197-207$. 
Lei, A. P., Hu, Z. L., Wong, Y. S., \& Tam, N. F. Y. (2007). Removal of fluoranthene and pyrene by different microalgal species. Bioresource Technology, 98(2), 273-280. https://doi.org/10.1016/j.biortech.2006.01.012

Leong, H. Y., Chang, C. K., Khoo, K. S., Chew, K. W., Chia, S. R., Lim, J. W., Chang, J. S., \& Show, P. L. (2021). Waste biorefinery towards a sustainable circular bioeconomy: a solution to global issues. Biotechnology for Biofuels, 14(1), 1-15.

Li, X., Xu, H., \& Wu, Q. (2007). Large-scale biodiesel production from microalga Chlorella protothecoides through heterotrophic cultivation in bioreactors. Biotechnology and bioengineering, 98(4), 764-771.

Lourenço, S. O. (2006). Cultivo de microalgas marinhas: princípios e aplicações (Vol. 1). São Carlos: RiMa.

Lowrey, J., Brooks, M. S., \& McGinn, P. J. (2014). Heterotrophic and mixotrophic cultivation of microalgae for biodiesel production in agricultural wastewaters and associated challenges - a critical review. Journal of Applied Phycology, 27(4), 1485-1498.

Lu, L., Wang, J., Yang, G., Zhu, B., \& Pan, K. (2017). Heterotrophic growth and nutrient productivities of Tetraselmis chuii using glucose as a carbon source under different C/N ratios. Journal of Applied Phycology, 29(1), 15-21.

Lu, Q., Zhou, W., Min, M., Ma, X., Chandra, C., Doan, Y. T. \& Ruan, R. (2015). Growing Chlorella sp. on meat processing wastewater for nutrient removal and biomass production. Bioresource technology, 198, 189-197.

Luo, L., Wang, P., Lin, L., Luan, T., Ke, L., \& Tam, N. F. Y. (2014). Removal and transformation of high molecular weight polycyclic aromatic hydrocarbons in water by live and dead microalgae. Process Biochemistry, 49(10), 1723-1732.

Lutzu, G. A., Ciurli, A., Chiellini, C., Di Caprio, F., Concas, A., \& Dunford, N. T. (2020). Latest developments in wastewater treatment and biopolymer production by microalgae. Journal of Environmental Chemical Engineering, 104926.

Mallick, S., Chakraborty, J., \& Dutta, T. K. (2011). Role of oxygenases in guiding diverse metabolic pathways in the bacterial degradation of low-molecularweight polycyclic aromatic hydrocarbons: A review. Critical Reviews in Microbiology, 37(1), 64-90. https://doi.org/10.3109/1040841X.2010.512268.

Markou, G. \& Georgakakis, D. (2011). Cultivation of filamentous cyanobacteria (blue-green algae) in agro-industrial wastes and wastewaters: A review. Applied Energy, 88, 3389-3401.

Marques, I. M., Melo, N. R., Oliveira, A. C. V., Moreira, Ícaro T. A. (2020) Bioremediation of urban river wastewater using Chlorella vulgaris microalgae to generate biomass with potential for biodiesel production. Research, Society and Development. 9 (7) p. 823974882 DOI: 10.33448/rsd-v9i7.4882.

Marques, I. M., Oliveira, A. C. V., Oliveira, O. M. C., Sales, E. A. \& Moreira, I. T. A. (2021). A photobioreactor using Nannochloropsis oculata marine microalgae for removal of polycyclic aromatic hydrocarbons and sorption of metals in produced water. Chemosphere, 281.

Mendhulkar, V. D., \& Shetye, L. A. (2017). Synthesis of biodegradable polymer polyhydroxyalkanoate (PHA) in cyanobacteria Synechococcus elongates under mixotrophic nitrogen-and phosphate-mediated stress conditions. Industrial Biotechnology, 13(2), 85-93.

Miao, M., Yao, X., Shu, L., Yan, Y., Wang, Z., Li, N., Cui, X., Lin, Y. \& Kong, Q. (2016). Mixotrophic growth and biochemical analysis of Chlorella vulgaris cultivated with synthetic domestic wastewater. Int. Biodeterior. International Biodeterioration \& Biodegradation, 1-6.

Miranda, V. J. M. de. (2008). Degradação de naftaleno, fenantreno e benzo(a)pireno em solos e sedimentos de ambientes costeiros, oceânicos e antárticos, 53.

Morales-Jiménez, M., Gouveia, L., Yáñez-Fernández, J., Castro-Muñoz, R., \& Barragán-Huerta, B. E. (2020). Production, preparation and characterization of microalgae-based biopolymer as a potential bioactive film. Coatings, $10(2), 120$.

Morales-Sánchez, D., Martinez-Rodriguez, O. A., Kyndt, J., \& Martinez, A. (2014). Heterotrophic growth of microalgae: metabolic aspects. World Journal of Microbiology and Biotechnology, 31(1), 1-9.

Morales-Sánchez, D., Tinoco-Valencia, R., Kyndt, J., \& Martinez, A. (2013). Heterotrophic growth of Neochloris oleoabundans using glucose as a carbon source. Biotechnology for biofuels, 6(1), 1-13.

Moreira, Í. T. A, Marques, I. M. (2019). Biorremediação de áreas costeiras impactadas por petróleo. Seminário Estudantil de Produção Acadêmica. 18, 132156.

Moreira, I. T. A., Oliveira, O. M. C., Azwell, T., Queiroz, A. F. S., Nano, R. M. W., Souza, E. S., Anjos, J. A. S. A., Assunção, R. V. \& Guimarães, L. M. (2016). Strategies of bioremediation for the degradation of petroleum hydrocarbons in the presence of metals in mangrove simulated. CLEAN-Soil, Air, Water, $44(6), 631-637$

Murwanashyaka, T., Shen, L., Yang, Z., Chang, J. S., Manirafasha, E., Ndikubwimana, T., Chen, C., \& Lu, Y. (2020). Kinetic modelling of heterotrophic microalgae culture in wastewater: Storage molecule generation and pollutants mitigation. Biochemical Engineering Journal, 157, 107523.

Mustafa, S., Bhatti, H. N., Maqbool, M., \& Iqbal, M. (2021). Microalgae biosorption, bioaccumulation and biodegradation efficiency for the remediation of wastewater and carbon dioxide mitigation: Prospects, challenges and opportunities. Journal of Water Process Engineering, 41(March), 102009. https://doi.org/10.1016/j.jwpe.2021.102009

Neilson, A. H., \& Lewin, R. A. (1974). The uptake and utilization of organic carbon by algae: an essay in comparative biochemistry. Phycologia, 13(3), 227264.

Nie, J., Sun, Y., Zhou, Y., Kumar, M., Usman, M., Li, J., Shao, J., Wang, L., \& Tsang, D. C. W. (2020). Bioremediation of water containing pesticides by microalgae: Mechanisms, methods, and prospects for future research. Science of the Total Environment. https://doi.org/10.1016/j.scitotenv.2019.136080

Ofman, P., Skoczko, I., \& Włodarczyk-Makuła, M. (2021). Biosorption of LMW PAHs on activated sludge aerobic granules under varying BOD loading rate conditions. Journal of Hazardous Materials, 418(June), 126332. https://doi.org/10.1016/j.jhazmat.2021.126332 
Oliveira, O. M. C., Queiroz, A. F. S., Cerqueira, J. R., Soares, S. A R., Garcia, K. S., Filho, A. P., Rosa, M. L. S., Suzart, C. M., Pinheiro, L. L. \& Moreira, I. T. A. (2020) Environmental disaster in the northeast coast of Brazil: Forensic geochemistry in the identification of the source of the oily material. Marine Pollution Bulletin, 160, 111597.

Parmar, A., Singh, N. K., Pandey, A., Gnansounou, E., \& Madamwar, D. (2011). Cyanobacteria and microalgae: a positive prospect for biofuels. Bioresource technology, 102(22), 10163-10172.

Perez-Garcia, O., Bashan, Y., \& Esther Puente, M. (2011). Organic carbon supplementation of sterilized municipal wastewater is essential for heterotrophic growth and removing ammonium by the microalga Chlorella vulgaris 1. Journal of phycology, 47(1), 190-199.

Perez-Garcia, O., Escalante, F. M. E., de-Bashan, L. E., \& Bashan, Y. (2011). Heterotrophic cultures of microalgae: Metabolism and potential products. Water Research, 45(1), 11-36.

Pignolet, O. et al. (2013). Highly valuable microalgae: biochemical and topological aspects. J. Ind Microbiol Biotechnol. 40, 781-796.

Pollard, T. D., Earnshaw, W. C., Lippincott-Schwartz, J., \& Johnson, G. (2016). Cell biology E-book. Elsevier Health Sciences.

Posten, C., \& Chen, S. F. (Eds.). (2016). Microalgae biotechnology.

Procházková, G. Brányiková, I., Zachleder, V. \& Brányik, T. (2014). Effect of nutrient supply status on biomass composition of eukaryotic green microalgae. Springer Science. DOI 10.1007/s10811-013-0154-9.

Rahman, A., Agrawal, S., Nawaz, T., Pan, S., \& Selvaratnam, T. (2020). A Review of Algae-Based Produced Water Treatment for Biomass and Biofuel Production. Water, 12(9), 2351.

Rempel, A., Gutkoski, J. P., Nazari, M. T., Biolchi, G. N., Cavanhi, V. A. F., Treichel, H., \& Colla, L. M. (2021). Current advances in microalgae-based bioremediation and other technologies for emerging contaminants treatment. Science of the Total Environment, $772,144918$. https://doi.org/10.1016/j.scitotenv.2020.144918

Romero, D. V., Cordero, A. P., \& Garizado, Y. O. (2018). Biodegradation activity of crude oil by Chlorella sp. under mixotrophic conditions. Indian J Sci Technol, 11, 1-8.

Rueda, E., García-Galán, M. J., Ortiz, A., Uggetti, E., Carretero, J., García, J., \& Díez-Montero, R. (2020). Bioremediation of agricultural runoff and biopolymers production from cyanobacteria cultured in demonstrative full-scale photobioreactors. Process Safety and Environmental Protection, 139, 241250.

Salvador, R. Puglieri, F. N. Halog, A. Andrade, F. G. Piekarski, C. M. Francisco, A. C. (2021). Key aspects for designing business models for a circular bioeconomy. Journal of Cleaner Production. 278, 124341.

Sankaran, R., Show, P. L., Nagarajan, D., \& Chang, J. S. (2018). Exploitation and biorefinery of microalgae. In Waste Biorefinery (pp. 571-601). Elsevier.

Satyanarayana, K. G., Mariano, A. B., \& Vargas, J. V. C. (2011). A review on microalgae, a versatile source for sustainable energy and materials. International Journal of energy research, 35(4), 291-311.

Schenk, P. M., Thomas-Hall, S. R., Stephens, E., Marx, U. C., Mussgnug, J. H., Posten, C., Kruse, O., \& Hankamer, B. (2008). Second generation biofuels: high-efficiency microalgae for biodiesel production. Bioenergy research, 1(1), 20-43.

Sharma, N. K., Rai, A. K., \& Stal, L. J. (2013). Cyanobacteria: an economic perspective. John Wiley \& Sons.

Shih, P. M. (2018). Towards a sustainable bio-based economy: redirecting primary metabolism to new products with plant synthetic biology. Plant Science, $273,84-91$

Shrivastav, A., Mishra, S. K., \& Mishra, S. (2010). Polyhydroxyalkanoate (PHA) synthesis by Spirulina subsalsa from Gujarat coast of India. International journal of biological macromolecules, 46(2), 255-260.

Silva, C. S. P., Silva-Stenico, M. E., Fiore, M. F., de Castro, H. F., \& Da Rós, P. C. M. (2014). Optimization of the cultivation conditions for Synechococcus sp. PCC7942 (cyanobacterium) to be used as feedstock for biodiesel production. Algal Research, 3, 1-7.

Silva, M. M., Leao, D. J., Moreira, I. T. A., Oliveira, O. M. C., Queiroz, A. F. S. \& Ferreira, S. L. C. (2015). Speciation analysis of inorganic antimony in sediment samples from São Paulo Estuary, Bahia State, Brazil. Environmental Science and Pollution Research, 22, 8386-8391.

Singh, A. K., Sharma, L., Mallick, N., \& Mala, J. (2017). Progress and challenges in producing polyhydroxyalkanoate biopolymers from cyanobacteria. Journal of Applied Phycology, 29(3), 1213-1232.

Singh, B. Bauddh, K. \& Bux, F. (2015). Algae and environmental sustainability. Springer.

Singh, J., \& Saxena, R. C. (2015). An introduction to microalgae: Diversity and significance. In Handbook of marine microalgae (pp. 11-24). Academic Press.

Singh, S. K., Kaur, R., Bansal, A., Kapur, S., \& Sundaram, S. (2020). Biotechnological exploitation of cyanobacteria and microalgae for bioactive compounds. In Biotechnological Production of Bioactive Compounds (pp. 221-259). Elsevier.

Singh, V., Chaudhary, D. K., Mani, I., \& Dhar, P. K. (2016). Recent advances and challenges of the use of cyanobacteria towards the production of biofuels. Renewable and Sustainable Energy Reviews, 60, 1-10.

Smith, R. T., Bangert, K., Wilkinson, S. J., \& Gilmour, D. J. (2015). Synergistic carbon metabolism in a fast growing mixotrophic freshwater microalgal species Micractinium inermum. Biomass and Bioenergy, 82, 73-86. 
Su, Y. (2021) Revisiting carbon, nitrogen, and phosphorus metabolisms in microalgae for wastewater treatment. Science of the Total Environment, 762, 1-14.

Subashchandrabose, S. R., Ramakrishnan, B., Megharaj, M., Venkateswarlu, K., \& Naidu, R. (2013). Mixotrophic cyanobacteria and microalgae as distinctive biological agents for organic pollutant degradation. Environment International, 51, 59-72.

Subramaniyan, V. (2012). Potential applications of cyanobacteria in industrial effluents-a review. Journal of Bioremediation and Biodegradation, 3(6).

Sun, Y., Yu, G., Xiao, G., Duan, Z., Dai, C., Hu, J., Wang, Y., Yang, Y., \& Jiang, X. (2021). Enhancing CO2 photo-biochemical conversion in a newlydesigned attached photobioreactor characterized by stacked horizontal planar waveguide modules. Science of The Total Environment, 760, 144041.

Suresh, B., \& Ravishankar, G. A. (2004). Phytoremediation — a novel and promising approach for environmental clean-up. Critical reviews in biotechnology, 24(2-3), 97-124.

Sutherland, D. L., \& Ralph, P. J. (2019). Microalgal bioremediation of emerging contaminants - Opportunities and challenges. Water Research. https://doi.org/10.1016/j.watres.2019.114921

Taher, H., Al-Zuhair, S., Al-Marzouqi, A. H., Haik, Y., \& Farid, M. (2014). Effective extraction of microalgae lipids from wet biomass for biodiesel production. Biomass and bioenergy, 66, 159-167.

Teo, C. L., \& Idris, A. (2014). Enhancing the various solvent extraction method via microwave irradiation for extraction of lipids from marine microalgae in biodiesel production. Bioresource Technology, 171, 477-481.

Tibbetts, P. J. C., Buchanan, I. T., Gawel, L. J., \& Large, R. (1992). A comprehensive determination of produced water composition. In Produced water (pp. 97-112). Springer, Boston, MA.

Ting, H., Haifeng, L., Shanshan, M., Zhang, Y., Zhidan, L., \& Na, D. (2017). Progress in microalgae cultivation photobioreactors and applications in wastewater treatment: A review. International Journal of Agricultural and Biological Engineering, 10(1), 1-29.

Uma, V. S., Gnanasekaran, D., Lakshmanan, U., \& Dharmar, P. (2020). Survey and isolation of marine cyanobacteria from eastern coast of India as a biodiesel feedstock. Biocatalysis and Agricultural Biotechnology, 24, 101541.

USEPA, United States Environmental Protection Agency (2008). Polycyclic aromatic hydrocarbons (PAHs). Office of solid waste. Washington DC.

Vadiveloo, A., Nwoba, E. G., Ogbonna, C., \& Mehta, P. (2019). Sustainable production of bioproducts from wastewater-grown microalgae. Sustain Downstream Process Microalgae Ind Appl, 7, 165.

Vázquez-Gómez, G., Rubio-Lightbourn, J., \& Espinosa-Aguirre, J. J. (2016). Mecanismos De Acción Del Receptor De Hidrocarburos De Arilos En El Metabolismo Del Benzo[a]Pireno Y El Desarrollo De Tumores. Tip, 19(1), 54-67. https://doi.org/10.1016/j.recqb.2016.02.006

Verâne, J., Santos, N. C. P., Silva, V. L., Almeida, M., Oliveira, O. M. C. \& Moreira, I. T. A. (2020 Phytoremediation of polycyclic aromatic hydrocarbons (PAHs) in mangrove sediments using Rhizophora mangle. Marine Pollution Bulletin, 160, 111687.

Verma, P. S., \& Agarwal, V. K. (2004). Cell Biology, Genetics, Molecular Biology, Evolution and Ecology: Evoloution and Ecology. S. Chand Publishing.

Wood, J. L., Miller, C. D., Sims, R. C., \& Takemoto, J. Y. (2015). Biomass and phycocyanin production from cyanobacteria dominated biofilm reactors cultured using oilfield and natural gas extraction produced water. Algal Research, 11, 165-168.

Xin, L., Hong-ying, H., Ke, G. \& Ying-Xue, S. (2010). Effects of different nitrogen and phosphorus concentrations on the growth, nutrient uptake, and lipid accumulation of a freshwater microalga Scenedesmus sp. Bioresource Technology, 101, 5494-5500.

Yang, I. S., Salama, E. S., Kim, J. O., Govindwar, S. P., Kurade, M. B., Lee, M., Roh, H. S. \& Jeon, B. H. (2016). Cultivation and harvesting of microalgae in photobioreactor for biodiesel production and simultaneous nutrient removal. Energy Conversion and Management, 117, 54-62.

Yu, H., Jia, S., \& Dai, Y. (2009). Growth characteristics of the cyanobacterium Nostoc flagelliforme in photoautotrophic, mixotrophic and heterotrophic cultivation. Journal of Applied Phycology, 21(1), 127-133.

Zhai, X., Zhu, C., Zhang, Y., Pang, H., Kong, F., Wang, J., \& Chi, Z. (2020). Seawater supplemented with bicarbonate for efficient marine microalgae production in floating photobioreactor on ocean: A case study of Chlorella sp. Science of The Total Environment, 738, 139439.

Zhang,C., Zhou,C., Burnap, R., \& Peng, L. (2018). Carbon/Nitrogen Metabolic Balance: Lessons from Cyanobacteria. CellPress Reviews, 1-15.

Zhou, W., Lu, Q., Han, P., \& Li, J. (2020). Microalgae cultivation and photobioreactor design. In Microalgae Cultivation for Biofuels Production (pp. 31-50). Academic Press. 